\title{
INTEROCEPTIVE ABILITY MODERATES THE EFFECT OF PHYSIOLOGICAL REACTIVITY ON SOCIAL JUDGMENT
}

\author{
Mallory J. Feldman
}

A thesis submitted to the Social Psychology faculty within The University of North Carolina at Chapel Hill in partial fulfillment of the requirements for a degree of Master of Arts in the Department of Psychology \& Neuroscience (Social Psychology).

\section{Chapel Hill}

2021

Approved by:

Kristen Lindquist

Keely A. Muscatell

Keith Payne

Kurt Gray 
(C) 2021

Mallory J. Feldman

ALL RIGHTS RESERVED 


\begin{abstract}
Mallory J. Feldman: Interoceptive Ability Moderates the Effect of Physiological Reactivity on Social Judgment

(Under the direction of Kristen Lindquist)

Social judgments - that others are kind or cruel, well-intentioned or conniving — can ease or disrupt social interactions. And yet a person's internal state can color these judgments - a phenomenon known as affective realism. We examined the factors that contribute to, and mitigate, affective realism during a stressful interview. We hypothesized and found that individuals' $(\mathrm{N}=161)$ ability to accurately perceive their own internal sensations influenced whether they attributed their own heightened stress reactions (i.e., sympathetic nervous system reactivity) to the behavior of two impassive interviewers. Participants who were poor heartbeat detectors perceived the interviewers as less helpful, polite, or professional, and more apathetic, judgmental, and aggressive when experiencing high levels of sympathetic nervous system reactivity during their interview. Being aware of one's internal state may be one pathway to more accurate, adaptive social interactions.
\end{abstract}


Thank you to my mentor, Dr. Kristen Lindquist, and the Carolina Affective Science lab; to Dr. Keely Muscatell and the Social Neuroscience and Health Lab; to my friends and colleagues, Dr. Jennifer MacCormack and Adrienne Bonar; to my family: Ruth Feldman, Rich Feldman, Jacob Feldman, Angus Finlay, and Mylo; and to the many other social support figures in my life inside and outside of North Carolina. 


\section{TABLE OF CONTENTS}

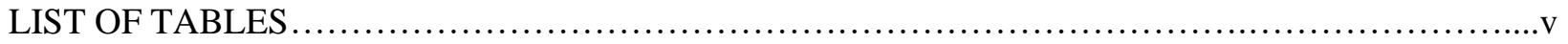

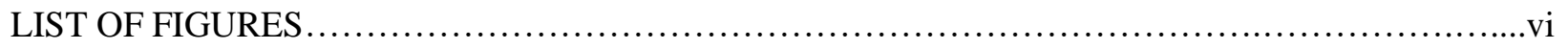

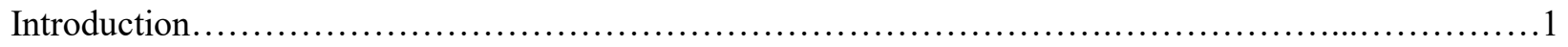

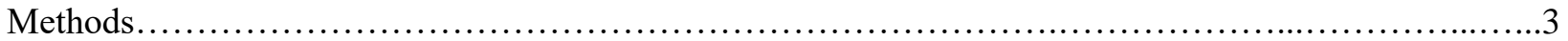

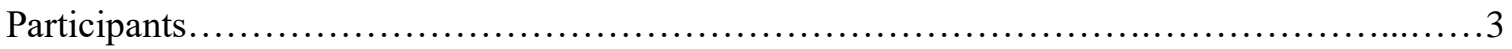

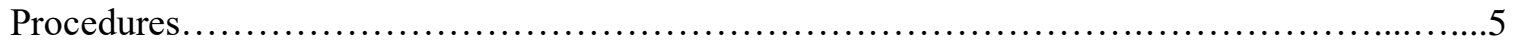

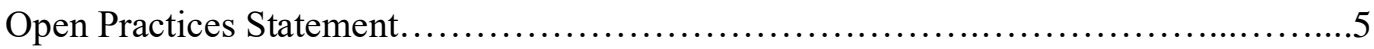

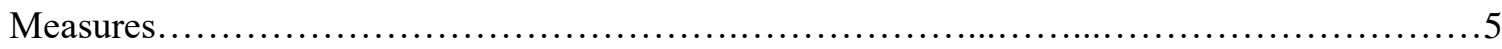

Heartbeat Detection Task...........................................................

Trier Social Stress Test (TSST) .....................................................

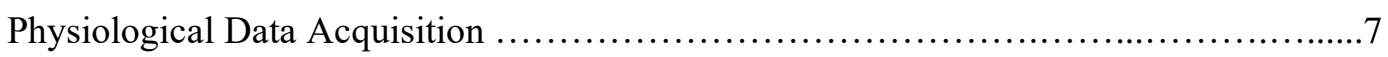

Physiological Data Processing .......................................................

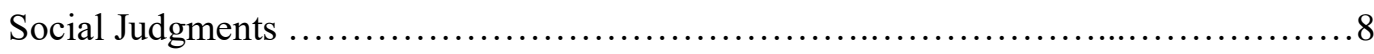

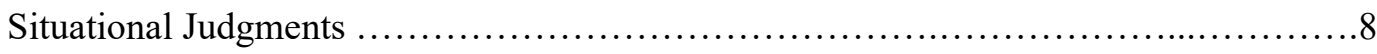

Open Ended Feelings Reports $\ldots \ldots \ldots \ldots \ldots \ldots \ldots \ldots \ldots \ldots \ldots \ldots \ldots \ldots \ldots \ldots \ldots \ldots \ldots \ldots \ldots . .8$

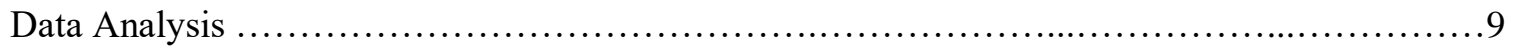

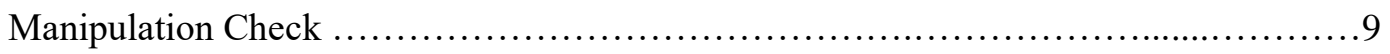

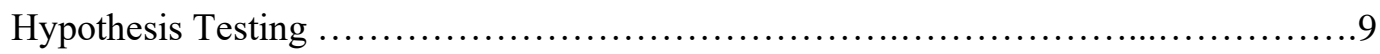

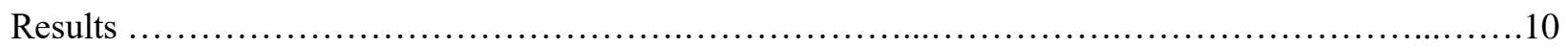

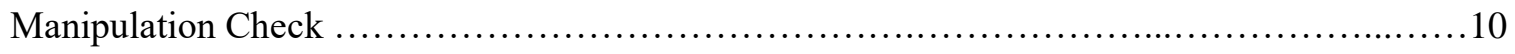

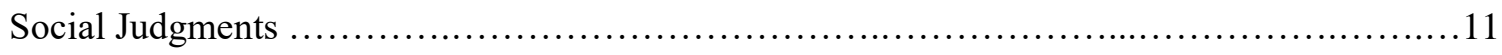

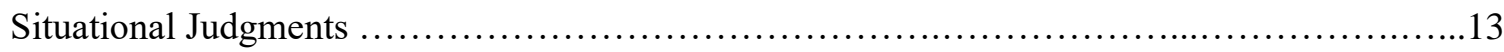




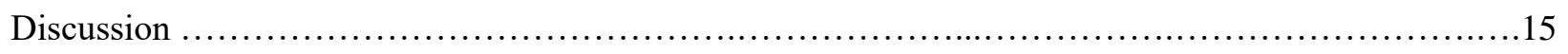

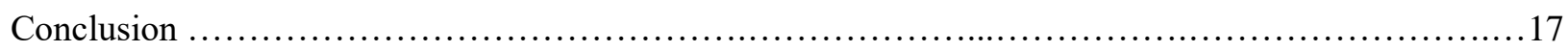

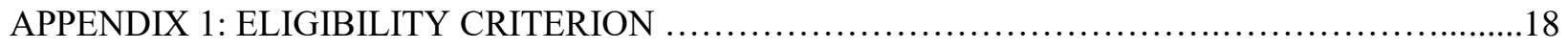

APPENDIX 2: DESCRIPTIVE STATISTICS FOR VARIABLES OF INTEREST ...................19

APPENDIX 3: OVERVIEW OF INTEROCEPTION MEASURES................................20

APPENDIX 4: RESULTS USING DIFFERENT MEASURES OF INTEROCEPTIVE ABILITY.........22

APPENDIX 5: RESULTS FOR NEGATIVE AND POSITIVE JUDGMENTS ............................26

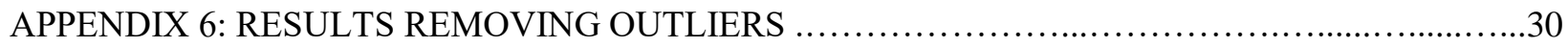

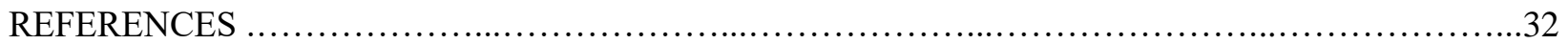




\section{LIST OF TABLES}

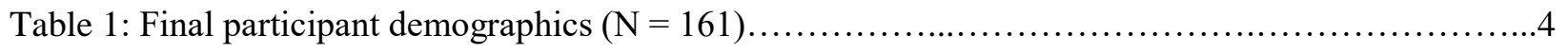

Table 2: Regression results using social judgments as the criterion.............................. 12

Table 3: Regression results using situational judgments as the criterion...........................13 


\section{LIST OF FIGURES}

Figure 1. Average valence, arousal, and SNS activity ( $-1 * \mathrm{PEP})$ before and after the Trier Social Stress Test (TSST). Text-based analysis of open-ended feelings reports revealed evidence for increases in negative valence (Panel A) and increases in arousal (Panel B) following the TSST. Analysis of physiological data revealed increases in SNS activity (i.e., decreases in PEP) following the TSST (Panel C)

Figure 2. Results of models testing the interaction between mean centered HBD accuracy and SNS reactivity ( -1 *PEP) on social and situational judgments. HBD accuracy interacted with SNS reactivity to influence social judgments. Individuals lower in HBD accuracy, who experienced greater SNS reactivity during the TSST rated interviewers more negatively (Panel A). This pattern of results did not generalize to situation ratings (Panel B) .14 


\section{Introduction}

People constantly make judgments about those around them—on any given day, a neighbor might seem "unfriendly," a spouse "grumpy," or a coworker "standoffish" (Abele et al., 2021; Feldman-Hall \& Shenhav, 2019; Thornton \& Tamir, 2020; Todorov et al., 2015). When these judgments are accurate, they can ease social interactions by helping a perceiver engage in mind perception and infer how to best behave (Waytz et al., 2010). Yet inaccurate judgments can derail social interactions or even cause people to lose their friends, livelihoods, or worse. The puzzle with social judgments is that they are not completely driven by target characteristics, but also by culture, context, and within-perceiver characteristics (Hehman et al., 2019). In the present study, we focus on one overlooked within-perceiver factor, the physiological state of the body. We find that awareness of one's internal state mitigates the effect of sympathetic nervous system reactivity on social judgments during stress.

What makes one person see another as a jerk? During social judgments, the brain relies on external sensory information about the context and the social target (e.g., facial morphology, voice) to make inferences about a target's behavior, disposition, and intentions (Aviezer et al., 2012; Hehman et al., 2019; Uleman et al., 2008; Wieser \& Brosch, 2012). Yet within-perceiver factors can also impact social judgments. For instance, it is well known that a person's stored knowledge (e.g., memories, stereotypes, or internalized cultural norms) can influence perceptions during social interaction (Brooks et al., 2019; Fiske, 1998; see Hinton, 2017). This is also true of one's current affective state (Anderson et al., 2012; Clore \& Huntsinger, 2007; Dutton \& Aron, 1974; Wormwood et al., 2018). However, it remains poorly understood how affect-based judgments occur. Here, we examined how internal affective sensations from the body (e.g., sympathetic nervous system reactivity) translated into social judgments.

The influence of affective sensations on perception is called affective realism (Barrett \& Bar, 2009). Affect encompasses feelings of pleasantness/unpleasantness (valence) and activation/deactivation (arousal) 
(Barrett, 2017; Barrett \& Bliss-Moreau, 2009; Posner et al., 2005). Affective realism occurs when affective experiences imbue the world - including social others — with affective meaning. The result is that people, places, and things seem more unpleasant in the presence of unpleasant feelings and more intense in the presence of aroused feelings (Schwarz \& Clore, 1983; Siegel \& Stefanucci, 2011; Wormwood et al., 2018).

Affective realism may seem maladaptive, but it likely evolved in service of maintaining the biological needs of the body (i.e., allostasis; Sterling, 2004, 2012; Sterling \& Laughlin, 2015). The brain efficiently enacts allostasis by anticipating (i.e., predicting) future bodily needs and preparing to meet them before they arise. For example, the brain constantly monitors the body's energy stores and releases neuropeptides to generate feelings of hunger that motivate food intake well before blood glucose drops below dangerous levels. Predictive regulation also extends to perception. When we're hungry, food is more appetizing and attention-grabbing (Reents et al., 2020). When we're dehydrated, a water bottle may appear closer and easier to reach (Balcetis \& Dunning, 2006). When we're metabolically taxed, a hill may seem especially steep (Proffitt et al., 2003). Using information about the current state of the body to drive perceptions of the outside world is advantageous in these non-social contexts because it aligns behavior with the body's needs. Affective realism can also be helpful in social contexts. For example, when the immune system is actively attacking a virus, trusted others seem especially appealing and unknown others especially threatening (Eisenberger et al., 2017).

Yet not all allostatic needs are relevant to the immediate social context, which means that affective realism can sometimes lead social judgments astray. For instance, people view peers more negatively when hungry v. satiated (MacCormack \& Lindquist, 2019) and are more likely to perceive sexual interest in others when they are sexually aroused v. calm (Bouffard \& Miller, 2014). Affective realism can even have deadly consequences: law enforcement officers are more likely to perceive citizens as threatening and erroneously use lethal force when they are experiencing elevated levels of cardiovascular activation during stress (Andersen et al., 2018; Haller et al., 2014). It is thus essential to understand when and why affective realism occurs to better intervene on these biasing, and even dangerous, instances. 
There is a long line of research showing that awareness of one's affective reactions to stimuli (e.g., the weather) that are incidental to the context can reduce the misattribution of affect to other judgments (e.g., of life satisfaction; Schwarz \& Clore, 1983). But how might one intervene when affective reactions are more integral to the situation at hand? In the present study, we examined affective realism during a stressful social interaction. Participants completed the Trier Social Stress Task (TSST; Kudielka et al., 2007) by performing an impromptu speech about their dream job and difficult mental math in front of two impassive interviewers. We acquired sympathetic nervous system (SNS) reactivity-a physiological marker of autonomic arousal - throughout. Participants subsequently rated the affective qualities of their interviewers, the stressor tasks, and their emotions. We operationalized social affective realism as the extent to which participants perceived the neutral behaviors of their interviewers to be more negative (e.g., less helpful, polite, or professional, and more apathetic, judgmental, and aggressive) following the TSST.

We hypothesized that SNS reactivity would predict affective realism - but only for subjects who were less sensitive to their bodies (i.e., who had poorer interoceptive ability) since interoceptive ability has been shown to help people disambiguate self from other and make more accurate mental state attributions (Babo-Rebelo et al., 2019; Tajadura-Jiménez \& Tsakiris, 2014). Specifically, we predicted and found that SNS reactivity leads to social affective realism, but only for those individuals who are relatively less accurate in detecting their own heartbeats. In contrast, SNS reactivity led to less affective realism for those individuals who were highly accurate in detecting their own heartbeats. We found that these effects were specific to social affective realism and did not impact perceptions of the social stressor. Interoceptive ability may thus be one path to mitigating social affective realism when stress runs high.

\section{Methods}

\section{Participants}

The present investigation was part of a larger study with a total sample of 250 young adults recruited in the United States from the University of North Carolina at Chapel Hill (UNC-CH) Department of Psychology and Neuroscience introductory psychology course participant pool (57.6\% female; 57.6\% European American, 13.6\% African American, 13.6\% Asian American, 6.4\% Latinx, 6.0\% biracial, and 
$2.8 \%$ that either identified with more than one race or with none of the races presented; Mage $=19.20$ years, $S D$ age $=1.29$ years ranging from 17 to 29 years old). Of the original 250 participants, 185 participants completed all measures relevant to the present analyses and of those, 161 participants provided complete and useable data. Final sample demographics can be found in Table 1.

All participants were screened for conditions that could impact stress reactivity or autonomic physiology (e.g., psychiatric illness, heart conditions or pacemakers, eating disorders, or body mass index (BMI) greater than 33). Participants completed two laboratory sessions. Prior to each session, participants were given instructions to avoid certain foods, substances, and health behaviors that could impact their autonomic physiology. Participants who failed to follow these instructions, who were currently ill, or who were taking any sort of medication were either excluded or rescheduled (full eligibility criterion can be found in the appendix).

Table 1. Final participant demographics $(N=161)$

\begin{tabular}{|c|c|c|c|c|}
\hline Variable & n $(\%)$ or mean & SD & Min & Max \\
\hline \multicolumn{5}{|l|}{ Self-reported Sex } \\
\hline Female & $95(59.0 \%)$ & - & & - \\
\hline Male & $66(41.00 \%)$ & - & & - \\
\hline Age (years) & 19.25 & 1.31 & 18.00 & 29.00 \\
\hline BMI $\left(\mathbf{k g} / \mathbf{m}^{2}\right)$ & 22.86 & 3.03 & 16.44 & 31.61 \\
\hline \multicolumn{5}{|l|}{ Race } \\
\hline American Indian \& Alaskan Indian & $0(0.00 \%)$ & - & & - \\
\hline Asian American & $18(11.20 \%)$ & - & & - \\
\hline Native Hawaiian or other Pacific Islander & $0(0.00 \%)$ & - & & - \\
\hline Black/African American & $23(14.3 \%)$ & - & & - \\
\hline White/European American & $101(62.7 \%)$ & - & & - \\
\hline Latin American & $8(5.00 \%)$ & - & & - \\
\hline More than one race & $10(6.20 \%)$ & - & & - \\
\hline Other race & $1(0.60 \%)$ & & & \\
\hline
\end{tabular}




\section{Procedures}

This study was approved by the UNC-CH Institutional Review Board (IRB\# 14-3243).

Participants completed two laboratory sessions. Compensation was four hours' worth of course-credit. During session one, participants reported on their current health and completed informed consent before being connected to an electrocardiograph for a 5-minute resting baseline period. Participants then completed three counterbalanced tasks: the modified Whitehead heartbeat detection (HBD) task, a survey evaluating interoceptive awareness and beliefs (unrelated to the present investigation), and a behavioral reaction time task (unrelated to the present investigation).

During session two, participants were again asked to report on their current health before completing an open-ended feelings report. Next, participants were connected to an electrocardiograph and impedance cardiograph for a second 5-minute resting baseline period. As required by the UNC-CH IRB, participants were then provided a second informed consent document. This document told subjects that they would be completing a series of cognitive behavioral tests that included public speaking. After providing consent, participants completed the gold-standard Trier Social Stress Test (TSST) followed by a second open-ended feelings report and a final set of questionnaires in which they were asked to make situational and social judgments. Participants were then debriefed and compensated for their time.

\section{Open Practices Statement.}

The analyses reported in this article were not formally pre-registered. Neither the data nor materials have been made available on a permanent third-party archive; requests for the data or materials can be sent via email to the lead author. Full code for analyses, diagnostics, and plots are available at https://osf.io/8ys5a/.

\section{Measures}

\section{Heartbeat Detection Task}

We assessed interoceptive ability using the modified Whitehead heartbeat detection task (HBD; Kleckner et al., 2015; Whitehead et al., 1977) programmed using a custom software in MATLAB (developed by Kleckner et al., 2015) in combination with the Mindware heartbeat detection software 
module (v. 3.0.13). Participants completed this task in a low-light private testing room with the door closed to minimize distractions. On each of sixty trials, participants heard ten tones through headphones. Tones were either played coincident with the subject's heartbeat (approximately $200 \mathrm{~ms}$ after ventricular depolarization) or not coincident with the subject's heartbeat (approximately $500 \mathrm{~ms}$ after ventricular depolarization). After each trial, participants indicated "yes" or "no" as to whether the tones did or did not coincide with their heartbeat. Trials where reaction times were faster than $200 \mathrm{~ms}$ or slower than $700 \mathrm{~ms}$ were excluded from analyses (5.11\% total trials). Four of the 185 subjects who completed sessions one and two and who completed all study components were excluded from the final sample for missing HBD data due to equipment malfunction. Interoceptive ability was operationalized as the percent of correct trials, or accuracy (trials where participants correctly indicated either coincidence or non-coincidence; see appendix for more information).

\section{Trier Social Stress Test (TSST)}

The TSST consists of two components: a speech task and a surprise mental math task. Prior to beginning these tasks, research assistants invited two "interviewers" into the testing room. These interviewers were described as experts in nonverbal communication, public performance, and cognitive ability. Interviewers dressed professionally and wore white laboratory coats over their clothing. Interviewers informed participants that they would be giving a ten-minute speech as part of a hypothetical interview for their dream job. Participants were given 2 minutes to mentally prepare. Afterwards, interviewers re-entered the room and instructed participants to begin. Participants were required to speak for the entire ten minutes as interviewers watched with neutral expressions-providing no feedback or encouragement. Following the speech task, participants were told they would be completing a mental math task. Specifically, participants were asked to count out loud from the number 996 backwards in steps of seven as fast as they could while making as few errors as possible. If participants provided an erroneous answer, they were asked to start again from 996. This task took five-minutes total and was modified slightly for participants who found the math too easy or too difficult. Continuous physiology was acquired throughout. 


\section{Physiological Data Acquisition.}

To derive our measure of cardiac sympathetic nervous system reactivity, cardiac data were acquired using Mindware Technologies (Gahanna, OH, USA) Biolab software. Electrocardiography (ECG) data were collected from three non-invasive spot electrodes placed in a modified lead-II configuration. One electrode was placed distally on the right collarbone and two electrodes were placed on the lower-most ribs (one on either side of the ribcage). Impedance cardiography (ICG) data was acquired using the four-spot electrode configuration described in Qu et al. (1986). Two inner recording electrodes were placed on the participant's front: one at the base of the neck at the top of the sternum, and one at the bottom of the sternum over the xiphisternal junction. Two outer recording electrodes were placed on the participant's back: one approximately $4 \mathrm{~cm}$ above the base of the neck and one approximately $4 \mathrm{~cm}$ below the bottom of the sternum.

\section{Physiological Data Processing}

All data was visually inspected and scored by trained scorers using Mindware Technologies’ Heart Rate Variability (v3.021) and Impedance (v3.2.4) analysis software. For all analyses, physiological measures reflect individual change scores from baseline. Physiological activity during the TSST was averaged across the first minutes of speech preparation, speech, and mental math before being baseline corrected. Where participants were missing data during the first minute of these tasks, the second minute was substituted.

As our cardiac SNS index, we extracted pre-ejection period (PEP) reactivity derived from the electrocardiograph and impedance cardiograph data. PEP reflects the time (in milliseconds) between the electrical impulse signaling contraction of the left ventricle and the opening of the aortic valve. Smaller PEP intervals suggest periods of increased cardiac contractility. Such changes are predominantly controlled by sympathetic innervation of the heart (Berntson et al., 2017; Cacioppo et al., 2017). Insofar as PEP is a relatively pure measure of SNS activity, it provides an intuitive measure of physiological arousal (see Satpute et al., 2019). For ease of interpretation, we inverted PEP in all subsequent analyses, tables, and figures, so that higher values would signal greater changes in SNS activity. Twenty one of the 
185 subjects who completed sessions one and two and who completed all study components were excluded from the final sample for missing PEP data due to poor physiological signal quality or technical malfunction.

\section{Social Judgments}

Following the TSST, participants were given a survey asking them to rate the TSST interviewers. Specifically, participants rated the extent to which they felt their interviewers were aggressive, helpful, lacking empathy, professional, polite, and judgmental. All ratings were made on 6-point Likert scales ranging from "Not at All" to "Extremely." Importantly, participants were informed that these social evaluative judgments were a "normal part of every experiment" and were encouraged to provide candid responses. Because we did not have specific hypotheses about individual social appraisals (e.g., helpfulness versus politeness), all negative items were reverse scored and social judgments were averaged such that higher scores indicated more positive evaluations. Analyses for positive and negative ratings separately can be found in the appendix.

\section{Situational Judgments}

In the same post-TSST survey described above, participants were also asked to evaluate the TSST tasks. Specifically, participants were asked to rate both the speech and the math task on their difficulty, stressfulness, and enjoyability. All ratings were made on 6-point Likert scales ranging from "Not at All" to "Extremely." As with the social ratings, we did not have specific hypotheses about individual situational appraisals (e.g., stressfulness versus difficulty) and so all negative items were reverse scored and ratings for situation judgments were averaged such that higher scores indicated more positive evaluations. Analyses for positive and negative ratings separately can be found in the appendix.

\section{Open Ended Feelings Reports}

Before and after completing the TSST, participants were instructed to, "Please write out in your own words how you feel right now. Please be as SPECIFIC and DESCRIPTIVE as possible about how you feel." On average, subjects wrote 43.12 words $(S D=24.71)$. All open-ended feelings reports were word tokenized (i.e., split into vectors of single words or "tokens") and merged with an open-source 
semantic lexicon using the tidytext package (version 0.3.1) in R (Silge \& Robinson, 2016). Semantic lexicons are large dictionaries of words which have been normed along various semantic dimensions. In the present analyses we used the NRC Valence, Arousal, and Dominance (NRC-VAD) Lexicon (Mohammad, 2018). The NRC-VAD Lexicon is a dictionary containing valence and arousal norms for more than 20,000 English words. Norms were generated from manual annotations and ranged from 0 (negative valence/low arousal) to 1 (positive valence/high arousal). We chose this lexicon because it had the greatest representation of words found in the feelings reports $(M=40 \%, S D=10 \%)$. Valence and arousal scores were averaged across all available words in each of the feelings reports to generate a proximal measure of individuals' mental state before and after the TSST. For ten subjects, the NRC-VAD had particularly poor coverage (i.e., normative ratings for $<5$ words). Feelings reports for these ten subjects, and for one additional subject who was missing data, were excluded from manipulation checks.

\section{Data Analysis}

\section{Manipulation Check}

To establish the effectiveness of the TSST at inducing stress, we first performed two-tailed paired-samples t-tests assuming equal variance to evaluate differences in text-based estimates of valence and arousal from participant's open-ended reports prior to and after the TSST.

We next performed a two-tailed paired sample t-test on SNS activity prior to and after the TSST. A significant Levene's test for homogeneity of variance suggested that population variance for SNS activity could not be assumed equal before and after the TSST; $F(1,298)=3.88, p=0.05$. Consequently, we conducted a two-tailed paired samples t-test using a Welch modification to the degrees of freedom.

\section{Hypothesis Testing}

All main hypotheses were tested using hierarchical multiple regression implemented using the stats package (version 3.6.2) in R (R Core Team, 2019). To increase interpretability of model coefficients and to address potential multicollinearities in the data, all continuous predictor variables were mean centered. Analyses were conducted separately using social judgments and situational judgments as criterion. In the first step, SNS reactivity (-1*PEP reactivity) and HBD accuracy were entered as 
predictors with their interaction term entered at step two. In step three, age, self-reported sex, and BMI were added as covariates. In supplementary analyses, we also examined models using a signal detection theoretic estimate of cardiac interoceptive sensitivity (d') and its non-parametric counterpart (a'). These analyses are available in the appendix. A sensitivity analysis performed in G*Power (Erdfelder et al., 1996) suggested adequate power $(>=0.80)$ with an alpha $=0.05$, sample size $=161$, to detect a significant effect with an effect size of $\mathrm{f}^{2}=0.049$ or larger.

All models were checked for multicollinearity, linearity of predictor variables, normality, homoscedasticity, and points with concerning influence. Significant interactions were probed using the interactions package (version 1.1.5) in R (Long, 2019). Specifically, we evaluated the slope of SNS reactivity at mean levels of HBD accuracy $+/$ - one standard deviation. Descriptive statistics for all variables of interest are presented in the appendix.

Both HBD accuracy and age were right skewed in our data (skew $=1.05$ and 3.09 respectively). BMI was normally distributed. All model residuals met assumptions for normality and homoscedasticity. No observations demonstrated undue influence for any of the models reported, however a few observations stood out as having moderately large residuals or leverage. Removing these observations did not alter the significance of reported effects. Models run without these observations are reported in the appendix. Finally, the unique effects for each predictor in each model appeared linear.

\section{Results}

\section{Manipulation Check}

Text-based analysis of open-ended feelings reports revealed evidence for increases in negative valence (Figure 1, Panel A) and increases in subjective arousal (Figure 1, Panel B) following the TSST. Confirming the effectiveness of the TSST, participants used significantly more negatively valanced language after $(M=0.44, S D=0.09)$ compared to before $(M=0.36, S D=0.09)$ the TSST; $t(149)=9.79$, $p<0.001, d=0.80$. Participants also used significantly higher arousal language after $(M=0.48, S D=$ $0.06)$ compared to before $(M=0.44, S D=0.05)$ the TSST; $t(149)=7.50, p<0.001, d=0.61$. 
Analysis of physiological data also revealed increases in SNS activity (i.e., decreases in PEP) following the TSST (Figure 1, Panel C). Confirming the effectiveness of the TSST, participants exhibited significantly greater SNS activity after $(M=-109.80, S D=13.80)$ compared to before $(M=$ $-120.92, S D=12.19)$ the TSST; $t(149)=11.73, p<0.001, d=0.96$.
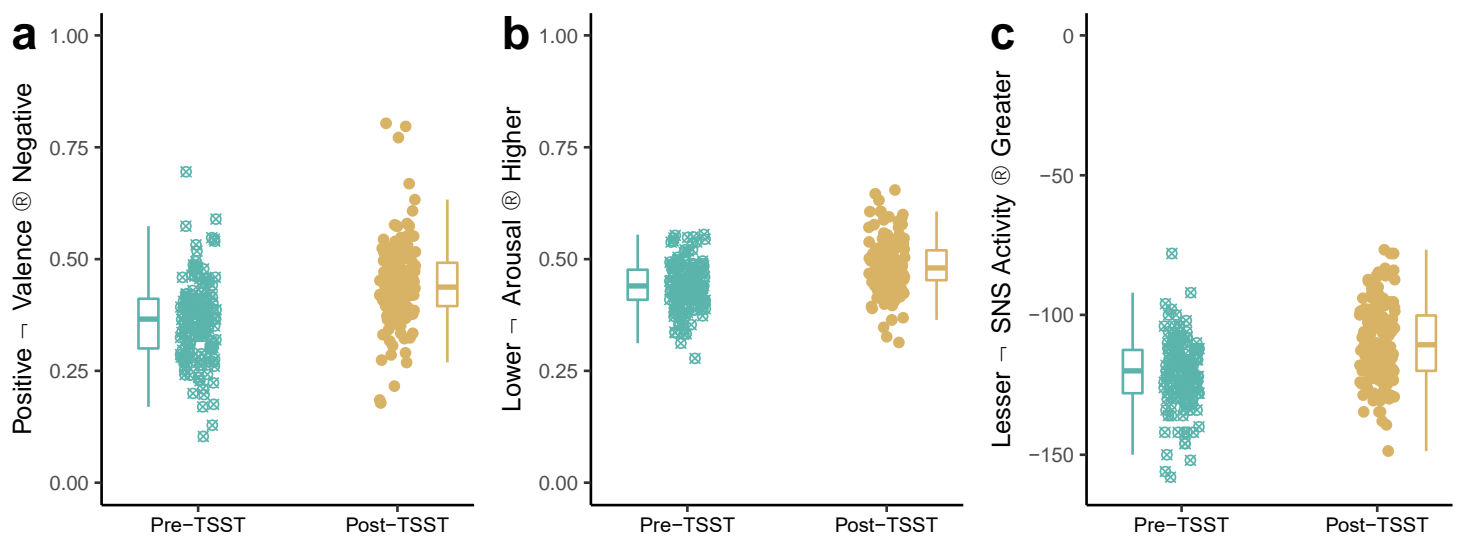

Figure 1. Average valence, arousal, and SNS activity (-1*PEP) before and after the Trier Social Stress Test (TSST). Text-based analysis of open-ended feelings reports revealed evidence for increases in negative valence (Panel A) and increases in arousal (Panel B) following the TSST. Analysis of physiological data revealed increases in SNS activity (i.e., decreases in PEP) following the TSST (Panel C).

\section{Social Judgments}

Neither SNS reactivity nor HBD accuracy significantly covaried with social judgments ( $p s>$ 0.250; see Table 2). However, as predicted, the effect of SNS reactivity on social judgments was significantly moderated by participants' degree of HBD accuracy ( $b=.20, S E=.08,95 \%$ CIs $[0.04,0.36]$, $t(157)=2.44, p=.016, s r^{2}=.04$; see Table 2$)$. Poorer interoceptive ability predicted greater affective realism. These effects were robust when age, Self-Reported Sex, and BMI were added to the model $(b=$. 19, $S E=.08,95 \%$ CIs $[0.02,0.35], t(157)=2.24, p=.027, s r^{2}=.03$; see Table 2). Adding covariates did not significantly improve model fit.

Simple slopes analysis of the interaction between HBD accuracy and SNS reactivity revealed that greater SNS activity impacted negative evaluations of the interviewers - but only for individuals who were less accurate at detecting their own cardiac signals. Specifically, the relationship between SNS 
reactivity and social judgments was only significant at levels of HBD accuracy one standard deviation below the mean: $\hat{b}=-0.03$, se $=0.01, t(157)=2.25, p=0.03$.

Table 2. Regression results using social judgments as the criterion

\begin{tabular}{|c|c|c|c|c|c|}
\hline \multirow[b]{2}{*}{ Predictor } & \multicolumn{4}{|c|}{$b$} & \multirow[b]{2}{*}{ Difference } \\
\hline & $b$ & $\begin{array}{c}95 \% \mathrm{CI} \\
{[\mathrm{LL}, \mathrm{UL}]}\end{array}$ & $s r^{2}$ & Model Fit & \\
\hline (Intercept) & $3.70 * *$ & {$[3.51,3.90]$} & & & \\
\hline HBD Accuracy & -0.18 & {$[-1.77,1.41]$} & .00 & & \\
\hline \multirow[t]{3}{*}{ SNS Reactivity } & -0.01 & {$[-0.03,0.01]$} & .01 & & \\
\hline & & & & $\mathrm{R} 2=.007$ & \\
\hline & & & & $95 \%$ CI $[.00, .04]$ & \\
\hline (Intercept) & $3.69 * *$ & {$[3.50,3.88]$} & & & \\
\hline HBD Accuracy & -0.51 & {$[-2.10,1.08]$} & .00 & & \\
\hline SNS Reactivity & -0.01 & {$[-0.02,0.01]$} & .00 & & \\
\hline \multirow[t]{3}{*}{ HBD x SNS Reactivity } & $0.20 *$ & {$[0.04,0.36]$} & .04 & & \\
\hline & & & & $\mathrm{R} 2=.044$ & $\Delta \mathrm{R} 2=.036^{*}$ \\
\hline & & & & $95 \%$ CI[.00,.11] & $95 \% \mathrm{CI}[-.02, .09]$ \\
\hline (Intercept) & $3.63 * *$ & {$[3.38,3.88]$} & & & \\
\hline HBD Accuracy & -0.40 & {$[-2.05,1.25]$} & .00 & & \\
\hline SNS Reactivity & -0.00 & {$[-0.02,0.01]$} & .00 & & \\
\hline Age & -0.05 & {$[-0.20,0.10]$} & .00 & & \\
\hline Self-reported Sex & 0.15 & {$[-0.25,0.55]$} & .00 & & \\
\hline BMI & 0.04 & {$[-0.03,0.10]$} & .01 & & \\
\hline \multirow[t]{3}{*}{ HBD x SNS Reactivity } & $0.19 *$ & {$[0.02,0.35]$} & .03 & & \\
\hline & & & & $\mathrm{R} 2=.056$ & $\Delta \mathrm{R} 2=.013$ \\
\hline & & & & $95 \%$ CI $[.00, .10]$ & $95 \% \mathrm{CI}[-.02, .05]$ \\
\hline
\end{tabular}

$\overline{\text { Note. Higher criterion values indicate more positive interviewer ratings. All continuous predictors are }}$ mean-centered. A significant $b$-weight indicates the beta-weight and semi-partial correlation are also significant. $b$ represents unstandardized regression weights. $s r^{2}$ serves as an effect size estimate and represents the semi-partial correlation squared. $L L$ and $U L$ indicate the lower and upper limits of a confidence interval, respectively. $*$ Indicates $p<.05$. ** indicates $p<.01$. 


\section{Situational Judgments}

To test the specificity of affective realism effects to social vs. non-social judgments, we next examined participants' ratings of the task itself, i.e., their situational judgments. Neither HBD accuracy, SNS reactivity, nor their interaction significantly covaried with situational judgments in any model tested (all $p s>0.100$; see Table 3). However, Self-Reported Sex was a significant predictor of situational ratings, with participants who self-identified as Male rating the situation more positively than participants who self-identified as Female $(b=0.55, S E=0.14,95 \% C I[0.27,0.83], t(154)=3.89, p<0.001)$.

Table 3. Results using situational judgments as the criterion

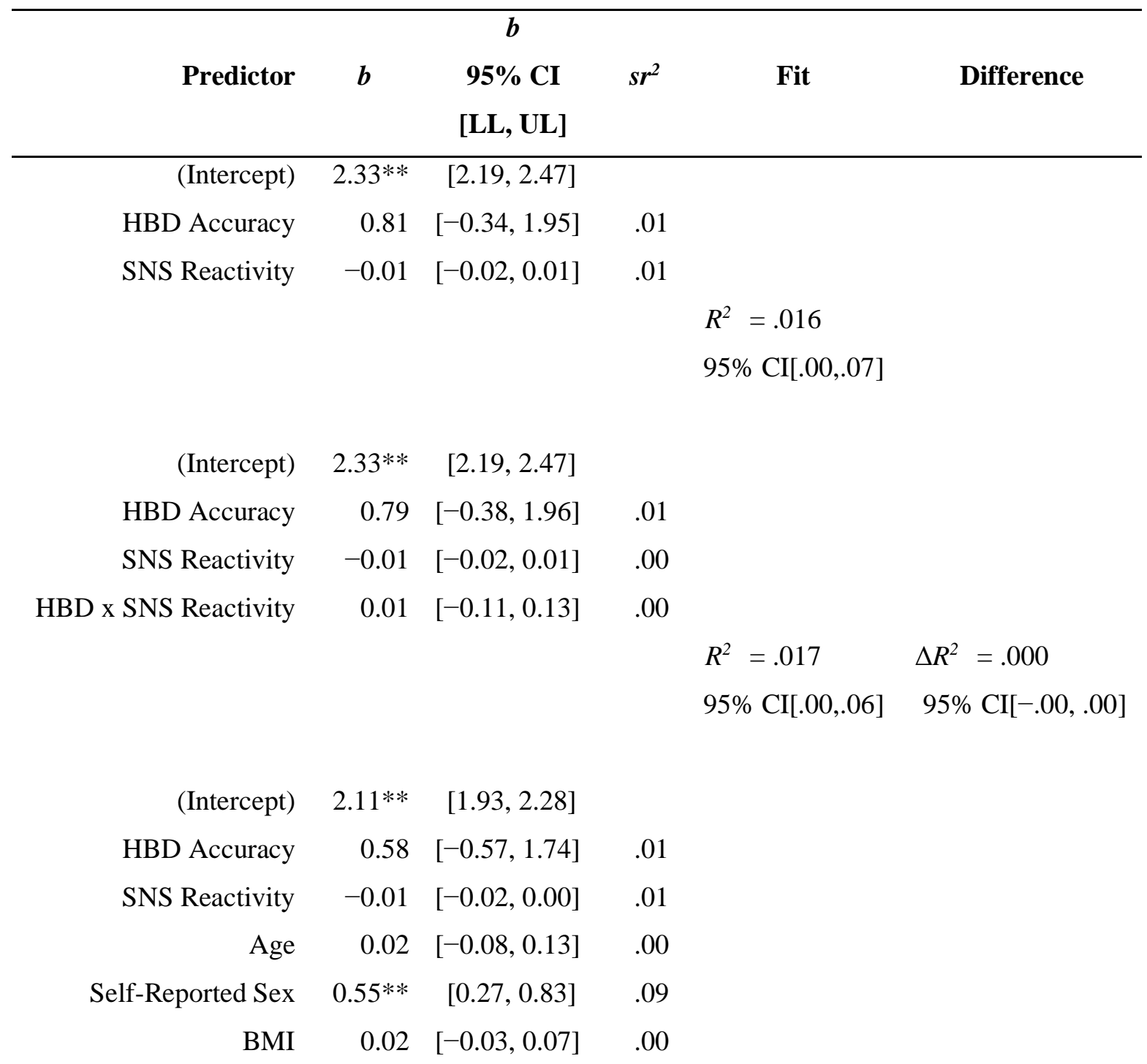


HBD x SNS Reactivity $\quad-0.01 \quad[-0.12,0.10] \quad .00$

$$
\begin{array}{ll}
R^{2}=.118^{* *} & \Delta R^{2}=.102 * * \\
95 \% \mathrm{CI}[.02, .19] & 95 \% \mathrm{CI}[.01, .19]
\end{array}
$$

Note. Higher criterion values indicate more positive situation ratings. All continuous predictors are meancentered. A significant $b$-weight indicates the beta-weight and semi-partial correlation are also significant. $b$ represents unstandardized regression weights. $s r^{2}$ serves as an effect size estimate and represents the semi-partial correlation squared. $L L$ and $U L$ indicate the lower and upper limits of a confidence interval, respectively. * Indicates $p<.05 . * *$ indicates $p<.01$.
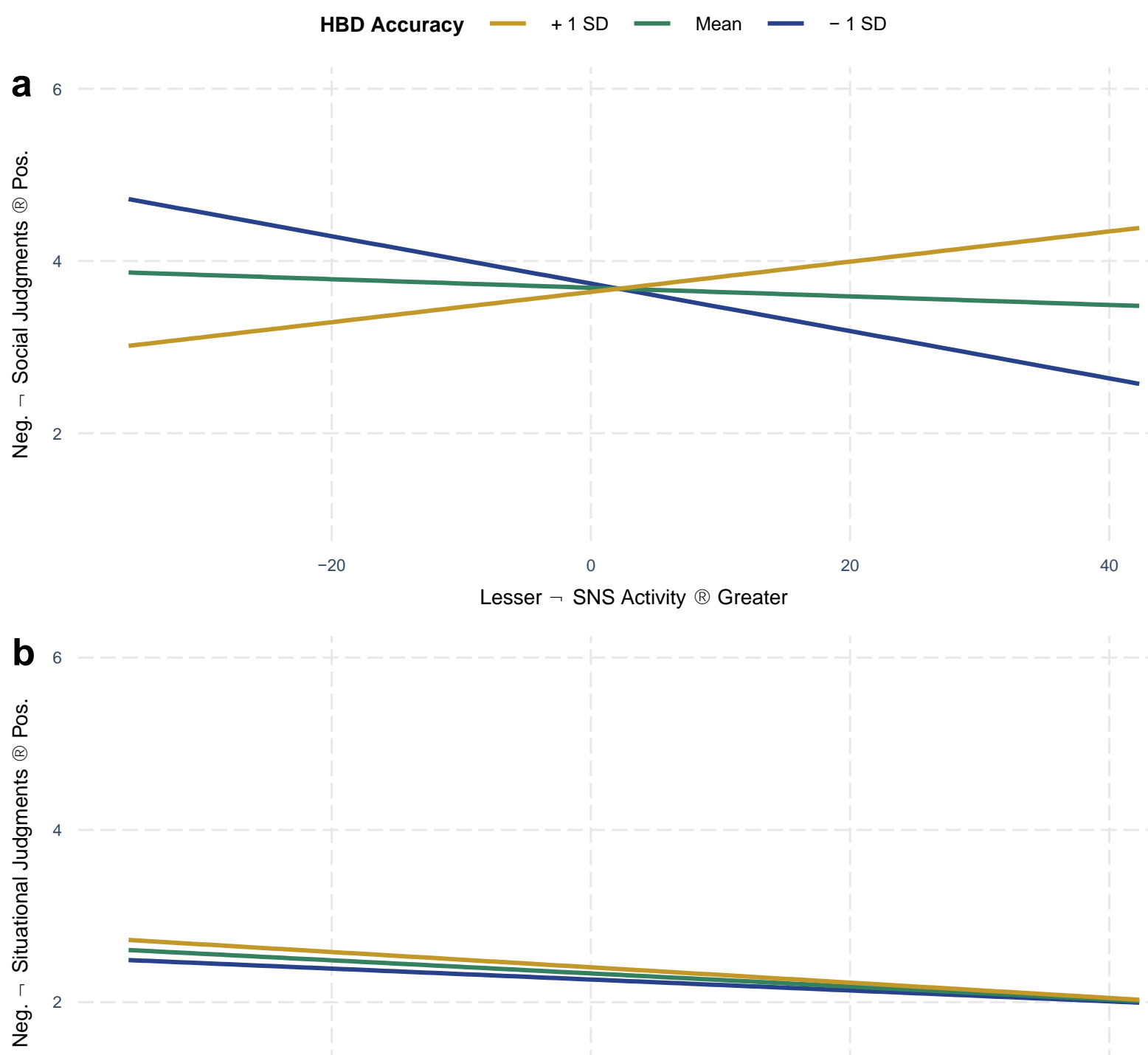
Figure 2. Results of models testing the interaction between mean centered HBD accuracy and SNS reactivity (-1*PEP) on social and situational judgments. HBD accuracy interacted with SNS reactivity to influence social judgments. Individuals lower in HBD accuracy, who experienced greater SNS reactivity during the TSST rated interviewers more negatively (Panel A). This pattern of results did not generalize to situation ratings (Panel B).

\section{Discussion}

Social affective realism occurs when people use their own internal states to make inferences about others' behaviors, intentions, and dispositions. The present study created a stressful social situation and tested whether physiological reactivity and interoceptive ability impacted social judgment (i.e., thinking that an interviewer was a bad person while feeling highly stressed). We hypothesized that individuals with greater SNS reactivity but lesser interoceptive ability would show the strongest social affective realism effects, reasoning that such individuals might unwittingly imbue their interviewers with negative affective meaning. In contrast, we reasoned that, individuals with higher interoceptive ability may be better able to localize discomforting physiological sensations - attributing them to the self as opposed to their interviewers.

Interestingly, there were no main effects of SNS reactivity or interoceptive ability on social judgments, suggesting that neither are alone sufficient to exacerbate affective realism. However, consistent with predictions, we found that individuals who were relatively unaware of their own heartbeats (i.e., who had low interoceptive ability) were more susceptible to social affective realism when experiencing robust SNS reactivity to the stressor. That is, in the face of strong physiology, individuals low in interoceptive ability perceived interviewers as less helpful, polite, or professional, and more apathetic, judgmental, and aggressive. In contrast, individuals with greater interoceptive ability were less likely to experience social affective realism - even when experiencing robust SNS reactivity.

One interpretation of these results is that interoceptive ability helps individuals (whether consciously or unconsciously) to better identify the locus of their internal physiological states. In contrast, individuals 
with poor interoceptive ability may experience greater affective realism because they struggled to determine the locus of their affective states during stress. Rather than experiencing their stress response - a high degree of SNS reactivity and feelings of unpleasantness and arousal—as a feature of their own internal bodily state, they perceived it to be evidence that the interviewers' behaviors were aggressive, unprofessional, and lacking in empathy. These findings are consistent with prior evidence that access to interoceptive information may support more accurate mental- and emotional- state attributions during social interactions (Allen \& Tsakiris, 2018; Babo-Rebelo \& Tallon-Baudry, 2018) and facilitate self-other differentiation (Babo-Rebelo et al., 2019; Tajadura-Jiménez \& Tsakiris, 2014; Tsakiris et al., 2011). However, this study is the first to our knowledge to examine the interaction between SNS reactivity and interoceptive ability on affective realism during an in vivo social interaction that mimics high-stress situations observed in daily life (e.g., job interviews, difficult conversations with peers).

Our findings also show specificity for social but not non-social judgments. Speculatively, affective realism may be most likely to occur in social contexts because social behavior is both affectively relevant (e.g., see Atzil et al., 2018) and inherently ambiguous (i.e., they rely on inferences about others' hidden internal experiences and intentions; Waytz et al. 2010). Interviewers herein were trained to be neutral in their behavior, meaning they were neither explicitly supportive nor critical of participants. These design principles are implemented during the Trier to maximize social evaluative threat while minimizing the kinds of social cues humans rely on to navigate stressful social situations (Dickerson \& Kemeny, 2004). These findings are thus consistent with prior evidence that interoceptive ability may facilitate more accurate perception of ambiguous social cues (Feldman et al., under review).

If interoceptive ability reduces susceptibility to affective realism when feelings run high- then cultivating interoceptive ability might help mitigate affective realism in situations where it is more likely to lead us astray. There are on-going interventions to increase interoceptive ability in adults using biofeedback or meditation-based techniques (e.g., breathing, mindfulness, body-scanning), albeit with mixed results (e.g., Khalsa et al., 2020; Quadt et al., 2021; Rominger et al., 2021). Socialization during childhood may also be critical: mothers' knowledge about the interoceptive correlates of emotions 
longitudinally predicts their children's social skills during middle school (MacCormack et al. 2020).

Other interventions that target the management of physiological arousal are also promising. For example, heart-rate variability biofeedback training during scenario-based threat exposures can generate long-term reductions in lethal force decision errors among active-duty police officers (Andersen et al., 2018).

While these findings help to advance research on affective realism, they are not without limitations. First, as in most laboratory studies our sample was not representative of all adults: our sample was limited to healthy young adults and over-represented some ethnic and racial identities and socio-economic statuses. Future research should thus replicate these findings in larger, more representative samples. Several social identity variables (e.g., age, gender, and SES) as well as myriad clinical conditions (e.g., anxiety, depression, functional motor disorders) have been linked to interoceptive ability and affective experience, making more inclusive sampling in future research both an ethical and empirical imperative (Grabauskaite et al., 2017; Khalsa et al., 2009; Khalsa et al., 2018; Leyva \& Hill, 2018; Moeini-Jazani et al., 2017; Murphy et al., 2019; Paulus et al., 2019; Proffitt Leyva \& Hill, 2018). Second, our study did not weigh in on the ultimate mechanism by which affective realism occurs. It would be interesting in future research to examine how SNS reactivity, interoception, and social affective realism are mediated by brain networks supporting affect, vision, and mentalizing (e.g., Provenzano et al., 2019).

\section{Conclusion}

Experiences of affective realism are both mundane and consequential, particularly when they bias social judgments that lead to real-world consequences. These data suggest that interoceptive ability may be an important individual difference that mitigates the extent to which physiological reactivity, under conditions of high stress, might bias social judgments. 


\section{APPENDIX 1: ELIGIBILITY CRITERION}

Participants were excluded during recruitment if they reported:

- $\quad$ BMI greater than 33

- Use of medications known to alter autonomic functioning (e.g., anti-depressants, Adderall, Warfarin)

- Any mental health issues (mood disorders, eating disorders, personality disorders, social anxiety disorders)

- Intense fear of public speaking and social situations

- Habitual smoking

- Substance abuse problems

- Heart conditions and/or a pacemaker

Participants were rescheduled or excluded prior to the lab sessions if they reported:

- Feeling sick or ill

- New use of medications known to alter autonomic functioning

- Drinking caffeine (e.g., coffee, caffeinated tea, an energy drink) within three hours of their lab visit

- Drinking a sugary drink (e.g., soda, juice, shake) within three hours of their lab visit

- Drinking alcohol within three hours of their lab visit

- Eating a heavy meal within three hours of their lab visit

- Physical exercise within three hours of their lab visit 


\section{APPENDIX 2: DESCRIPTIVE STATISTICS FOR VARIABLES OF INTEREST}

Appendix Table 1. Descriptive Statistics for variables of interest.

\begin{tabular}{lccccccc}
\hline Variable & mean & sd & min & max & skew & kurtosis & se \\
\hline HBD dprime & 0.56 & 0.79 & -0.74 & 4.20 & 1.85 & 0.56 & 0.79 \\
$\log 10$ (HBD dprime) & 0.15 & 0.20 & -0.58 & 0.72 & 0.03 & 0.15 & 0.20 \\
HBD aprime & 0.64 & 0.16 & 0.27 & 1.00 & 0.17 & 0.64 & 0.16 \\
HBD Accuracy & 0.60 & 0.12 & 0.36 & 1.00 & 1.05 & 0.60 & 0.12 \\
Soc Judgments - Total & 3.70 & 1.24 & 0.33 & 6.00 & -0.26 & 3.70 & 1.24 \\
Soc Judgments - Pos & 3.21 & 1.49 & 0.00 & 6.00 & -0.03 & 3.21 & 1.49 \\
Soc Judgments - Neg & 1.81 & 1.35 & 0.00 & 6.00 & 0.62 & 1.81 & 1.35 \\
Sit Judgments - Total & 2.33 & 0.90 & 0.67 & 4.50 & 0.37 & 2.33 & 0.90 \\
Sit Judgments - Pos & 2.20 & 1.02 & 1.00 & 5.00 & 0.64 & 2.20 & 1.02 \\
Sit Judgments - Neg & 3.60 & 1.03 & 1.00 & 6.00 & -0.21 & 3.60 & 1.03 \\
SNS Reactivity & 11.00 & 11.6 & -24.7 & 53.3 & 0.50 & 11.00 & 11.6 \\
\hline
\end{tabular}




\section{APPENDIX 3: OVERVIEW OF INTEROCEPTION MEASURES.}

There are many ways of measuring interoceptive ability. Below are descriptions of the three most popular methods for computing interoceptive ability from the Whitehead Heartbeat Detection (HBD) Task. These three methods are highly correlated (in general and in our sample ${ }^{1}$ ). We chose to use accuracy because it is the easiest to understand. However, note that these different measures have different distributional properties.

Appendix Figure 1. Distributions and inter-relationships among measures of interoceptive ability
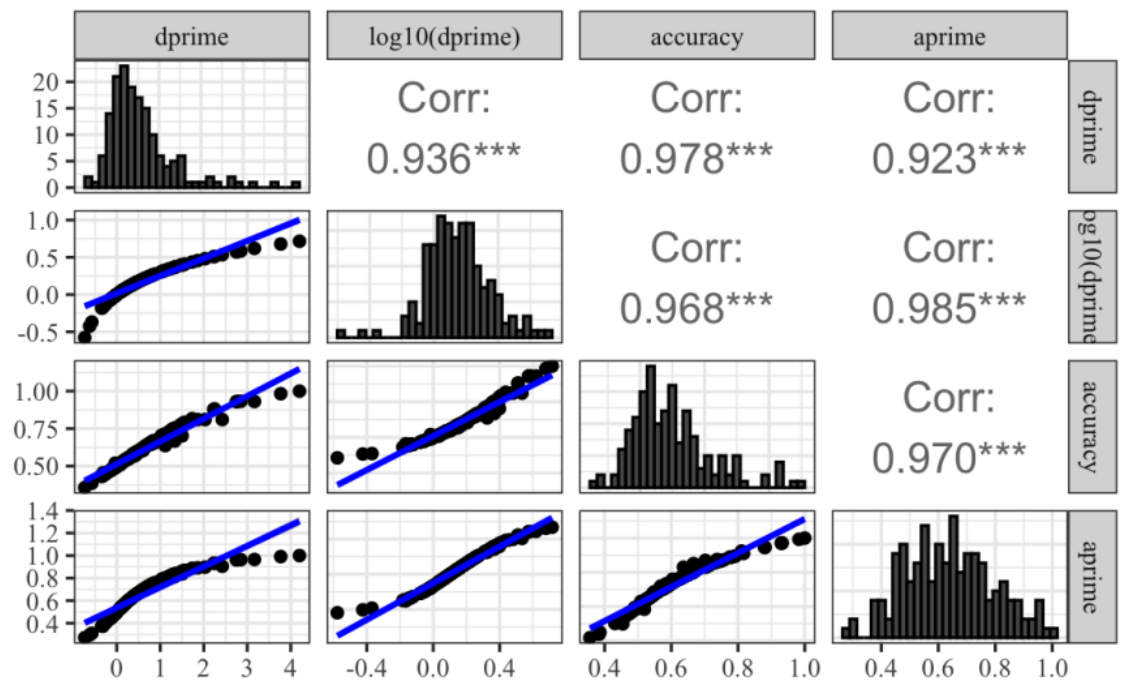

To compute measures of interoceptive ability, first each trial of the HBD task is categorized according to the rules outlined in supplementary table 2 . Then, metrics are computed using the equations in supplementary table 3 .

Appendix Table 2. Rules for categorizing HBD trials

\begin{tabular}{ll|cc}
\hline & \multicolumn{2}{c}{ Subject Response } \\
& & Concurrent & Non-Concurrent \\
\hline \multirow{2}{*}{ Trial-Type } & $\begin{array}{l}\text { Concurrent } \\
\text { Non-Concurrent }\end{array}$ & Hit & Miss \\
& False Alarm (FA) & Correct Rejection (CR) \\
\hline
\end{tabular}

\footnotetext{
${ }^{1}$ Interoceptive ability metrics based in signal detection theory were computed using the `psycho`package in R:

Makowski, (2018). The psycho Package: An Efficient and Publishing-Oriented Workflow for Psychological Science. Journal of Open-Source Software, 3(22), 470. https://doi.org/10.21105/joss.00470
} 
Appendix Table 3. Equations for computing interoceptive ability

\begin{tabular}{ll}
\hline Measure & Equation \\
\hline HBD Accuracy & Accuracy $=(H i t+C R) /(H i t+C R+F A+M i s s)$
\end{tabular}

Hit rate $\quad$ hit rate $=\left(\frac{\text { Hit }}{\text { Hit }+ \text { Miss }}\right)$

False alarm rate $\quad$ FA rate $=\left(\frac{F A}{F A+C R}\right)$

HBD dprime $\quad d^{\prime}=z($ hit rate $)-(F$ A rate $)$

HBD aprime $\quad a^{\prime}=\frac{1}{2}+\frac{(\text { hit rate }-F A \text { rate }) *(1+\text { hit rate }- \text { FA rate })}{4 * \text { hit rate } *(1-\text { hit rate })}$ 


\section{APPENDIX 4: RESULTS USING DIFFERENT MEASURES OF INTEROCEPTIVE ABILITY}

Appendix Table 4. Regression results using $\log 10(d$ ') with total social judgments as the criterion

\begin{tabular}{|c|c|c|c|c|c|}
\hline Predictor & $\boldsymbol{b}$ & $\begin{array}{c}b \\
95 \% \mathrm{CI} \\
{[\mathrm{LL}, \mathrm{UL}]}\end{array}$ & $s r^{2}$ & Fit & Difference \\
\hline \multirow{4}{*}{ SNS Reactivity } & $3.70 * *$ & {$[3.51,3.90]$} & & & \\
\hline & -0.09 & $\begin{array}{r}{[-1.07} \\
0.89]\end{array}$ & .00 & & \\
\hline & -0.01 & $\begin{array}{r}{[-0.03} \\
0.01]\end{array}$ & .01 & & \\
\hline & & & & $\begin{array}{c}R^{2}=.007 \\
95 \% \mathrm{CI}[.00, .04]\end{array}$ & \\
\hline (Intercept) & $3.70 * *$ & {$[3.51,3.89]$} & & & \\
\hline Log 10 dprime & -0.39 & $\begin{array}{r}{[-1.39} \\
0.62]\end{array}$ & .00 & & \\
\hline SNS Reactivity & -0.01 & $\begin{array}{r}{[-0.02} \\
0.01]\end{array}$ & .00 & & \\
\hline \multirow[t]{2}{*}{$\begin{array}{r}\text { Log10 dprime x SNS } \\
\text { Reactivity }\end{array}$} & $0.10 *$ & {$[0.01,0.18]$} & .03 & & \\
\hline & & & & $\begin{array}{c}R^{2}=.037 \\
95 \% \mathrm{CI}[.00, .10]\end{array}$ & $\begin{array}{c}\Delta R^{2}=.030 * \\
95 \% \mathrm{CI}[-.02, .08]\end{array}$ \\
\hline (Intercept) & $3.64 * *$ & {$[3.39,3.90]$} & & & \\
\hline Log 10 dprime & -0.31 & $\begin{array}{r}{[-1.35} \\
0.73]\end{array}$ & .00 & & \\
\hline SNS Reactivity & -0.01 & $\begin{array}{r}{[-0.02,} \\
0.01]\end{array}$ & .00 & & \\
\hline Age & -0.05 & $\begin{array}{r}{[-0.20} \\
0.11]\end{array}$ & .00 & & \\
\hline Self-Reported Sex & 0.15 & $\begin{array}{r}{[-0.25} \\
0.55]\end{array}$ & .00 & & \\
\hline BMI & 0.04 & $\begin{array}{r}{[-0.03} \\
0.10]\end{array}$ & .01 & & \\
\hline \multirow[t]{2}{*}{$\begin{array}{r}\text { Log10 dprime x SNS } \\
\text { Reactivity }\end{array}$} & 0.09 & $\begin{array}{r}{[-0.00} \\
0.17]\end{array}$ & .02 & & \\
\hline & & & & $\begin{array}{c}R^{2}=.049 \\
95 \% \mathrm{CI}[.00, .09]\end{array}$ & $\begin{array}{c}\Delta R^{2}=.012 \\
95 \% \mathrm{CI}[-.02, .05]\end{array}$ \\
\hline
\end{tabular}

Note. Higher criterion values indicate more positive interviewer ratings. All continuous predictors are mean-centered. A significant $b$-weight indicates the beta-weight and semi-partial correlation are also significant. $b$ represents unstandardized regression weights. $s r^{2}$ serves as an effect size estimate and represents the semi-partial correlation squared. $L L$ and $U L$ indicate the lower and upper limits of a confidence interval, respectively. * Indicates $p<.05$. ** indicates $p<.01$. 
Appendix Table 5. Regression results using log10(d') with total situation judgments as the criterion.

\begin{tabular}{|c|c|c|c|c|c|}
\hline Predictor & $b$ & $\begin{array}{c}b \\
95 \% \mathrm{CI} \\
{[\mathrm{LL}, \mathrm{UL}]}\end{array}$ & $s r^{2}$ & Fit & Difference \\
\hline (Intercept) & $2.33 * *$ & {$[2.19,2.47]$} & & & \\
\hline Log10 dprime & 0.49 & {$[-0.22,1.20]$} & .01 & & \\
\hline \multirow[t]{3}{*}{ SNS Reactivity } & -0.01 & {$[-0.02,0.01]$} & .00 & & \\
\hline & & & & $R^{2}=.016$ & \\
\hline & & & & $95 \%$ CI[.00,.07] & \\
\hline (Intercept) & $2.33 * *$ & {$[2.19,2.47]$} & & & \\
\hline Log $10 \mathrm{~d}$ prime & 0.50 & {$[-0.24,1.23]$} & .01 & & \\
\hline SNS Reactivity & -0.01 & {$[-0.02,0.01]$} & .00 & & \\
\hline \multirow{2}{*}{$\begin{array}{l}\text { Log10 d prime } x \\
\text { SNS Reactivity }\end{array}$} & -0.00 & {$[-0.07,0.06]$} & .00 & & \\
\hline & & & & $\begin{array}{l}R^{2}=.016 \\
95 \% \mathrm{CI}[.00, .06]\end{array}$ & $\begin{array}{l}\Delta R^{2}=.000 \\
95 \% \mathrm{CI}[-.00, .00]\end{array}$ \\
\hline (Intercept) & $2.11 * *$ & {$[1.93,2.28]$} & & & \\
\hline Log10 d prime & 0.39 & {$[-0.33,1.11]$} & .01 & & \\
\hline SNS Reactivity & -0.01 & {$[-0.02,0.00]$} & .01 & & \\
\hline Age & 0.02 & {$[-0.08,0.13]$} & .00 & & \\
\hline Self-Reported Sex & $0.56^{* *}$ & {$[0.28,0.84]$} & .09 & & \\
\hline BMI & 0.02 & {$[-0.03,0.07]$} & .00 & & \\
\hline \multirow[t]{3}{*}{$\begin{array}{l}\text { Log10 d prime } x \\
\text { SNS Reactivity }\end{array}$} & -0.02 & {$[-0.08,0.04]$} & .00 & & \\
\hline & & & & $R^{2}=.120^{* *}$ & $\Delta R^{2}=.104^{* *}$ \\
\hline & & & & $95 \%$ CI[.02,.19] & $95 \%$ CI[.02, .19] \\
\hline
\end{tabular}

Note. Higher criterion values indicate more positive situation ratings. All continuous predictors are meancentered. A significant $b$-weight indicates the beta-weight and semi-partial correlation are also significant. $b$ represents unstandardized regression weights. $s r^{2}$ serves as an effect size estimate and represents the semi-partial correlation squared. $L L$ and $U L$ indicate the lower and upper limits of a confidence interval, respectively. ${ }^{*}$ Indicates $p<.05 . * *$ indicates $p<.01$. 
Appendix Table 6. Regression results using $a^{\prime}$ ' with total social judgments as the criterion.

\begin{tabular}{|c|c|c|c|c|c|}
\hline Predictor & $b$ & $\begin{array}{c}b \\
95 \% \mathrm{CI} \\
{[\mathrm{LL}, \mathrm{UL}]}\end{array}$ & $s r^{2}$ & Fit & Difference \\
\hline (Intercept) & $3.70 * *$ & {$[3.51,3.90]$} & & & \\
\hline a prime & -0.17 & {$[-1.41,1.07]$} & .00 & & \\
\hline \multirow[t]{2}{*}{ SNS Reactivity } & -0.01 & {$[-0.03,0.01]$} & .01 & & \\
\hline & & & & $\begin{array}{l}R^{2}=.008 \\
95 \% \mathrm{CI}[.00, .05]\end{array}$ & \\
\hline (Intercept) & $3.69 * *$ & {$[3.50,3.88]$} & & & \\
\hline a prime & -0.42 & {$[-1.66,0.82]$} & .00 & & \\
\hline \multirow{3}{*}{$\begin{array}{r}\text { SNS Reactivity } \\
\text { a prime x SNS } \\
\text { Reactivity }\end{array}$} & -0.01 & {$[-0.02,0.01]$} & .00 & & \\
\hline & $0.15^{*}$ & {$[0.03,0.27]$} & .04 & & \\
\hline & & & & $\begin{array}{l}R^{2}=.046 \\
95 \% \mathrm{CI}[.00, .11]\end{array}$ & $\begin{array}{l}\Delta R^{2}=.039 * \\
95 \% \mathrm{CI}[-.02, .10]\end{array}$ \\
\hline (Intercept) & $3.64 * *$ & {$[3.39,3.89]$} & & & \\
\hline a prime & -0.34 & {$[-1.63,0.94]$} & .00 & & \\
\hline SNS Reactivity & -0.01 & {$[-0.02,0.01]$} & .00 & & \\
\hline Age & -0.04 & {$[-0.19,0.11]$} & .00 & & \\
\hline Self-Reported Sex & 0.14 & {$[-0.26,0.54]$} & .00 & & \\
\hline BMI & 0.04 & {$[-0.03,0.10]$} & .01 & & \\
\hline \multirow[t]{2}{*}{$\begin{array}{r}\text { a prime x SNS } \\
\text { Reactivity }\end{array}$} & $0.14 *$ & {$[0.02,0.26]$} & .03 & & \\
\hline & & & & $\begin{array}{l}R^{2}=.057 \\
95 \% \mathrm{CI}[.00, .11]\end{array}$ & $\begin{array}{l}\Delta R^{2}=.011 \\
95 \% \mathrm{CI}[-.02, .04]\end{array}$ \\
\hline
\end{tabular}

Note. Higher criterion values indicate more positive interviewer ratings. All continuous predictors are mean-centered. A significant $b$-weight indicates the beta-weight and semi-partial correlation are also significant. $b$ represents unstandardized regression weights. $s r^{2}$ serves as an effect size estimate and represents the semi-partial correlation squared. $L L$ and $U L$ indicate the lower and upper limits of a confidence interval, respectively. * Indicates $p<.05$. ** indicates $p<.01$. 
Appendix Table 7. Regression results using $a^{\prime}$ ' with total situation judgments as the criterion.

\begin{tabular}{|c|c|c|c|c|c|}
\hline Predictor & $b$ & $\begin{array}{c}b \\
95 \% \mathrm{CI} \\
{[\mathrm{LL}, \mathrm{UL}]}\end{array}$ & $s r^{2}$ & Fit & Difference \\
\hline (Intercept) & $2.33 * *$ & {$[2.19,2.47]$} & & & \\
\hline a prime & 0.63 & {$[-0.27,1.52]$} & .01 & & \\
\hline SNS Reactivity & -0.01 & {$[-0.02,0.01]$} & .01 & & \\
\hline & & & & $R^{2}=.016$ & \\
\hline & & & & $95 \%$ CI[.00,.07] & \\
\hline (Intercept) & $2.33 * *$ & {$[2.19,2.47]$} & & & \\
\hline a prime & 0.61 & {$[-0.30,1.52]$} & .01 & & \\
\hline SNS Reactivity & -0.01 & {$[-0.02,0.01]$} & .00 & & \\
\hline \multirow[t]{3}{*}{ a prime x SNS Reactivity } & 0.01 & {$[-0.08,0.10]$} & .00 & & \\
\hline & & & & $R^{2}=.017$ & $\Delta R^{2}=.000$ \\
\hline & & & & $95 \%$ CI[.00,.06] & $95 \% \mathrm{CI}[-.01, .01]$ \\
\hline (Intercept) & $2.11 * *$ & {$[1.93,2.29]$} & & & \\
\hline a prime & 0.44 & {$[-0.46,1.33]$} & .01 & & \\
\hline SNS Reactivity & -0.01 & {$[-0.02,0.00]$} & .01 & & \\
\hline Age & 0.02 & {$[-0.08,0.13]$} & .00 & & \\
\hline Self-Reported Sex & $0.55^{* *}$ & {$[0.27,0.83]$} & .09 & & \\
\hline BMI & 0.02 & {$[-0.03,0.07]$} & .00 & & \\
\hline \multirow[t]{3}{*}{ a prime $x$ SNS Reactivity } & -0.01 & {$[-0.09,0.08]$} & .00 & & \\
\hline & & & & $R^{2}=.118^{* *}$ & $\Delta R^{2}=.101 * *$ \\
\hline & & & & 95\% CI[.02,.19] & $95 \%$ CI[.01, .19] \\
\hline
\end{tabular}

Note. Higher criterion values indicate more positive situation ratings. All continuous predictors are meancentered. A significant $b$-weight indicates the beta-weight and semi-partial correlation are also significant. $b$ represents unstandardized regression weights. $s r^{2}$ serves as an effect size estimate and represents the semi-partial correlation squared. $L L$ and $U L$ indicate the lower and upper limits of a confidence interval, respectively. $*$ Indicates $p<.05 . * *$ indicates $p<.01$. 


\section{APPENDIX 5: RESULTS FOR NEGATIVE AND POSITIVE JUDGMENTS SEPERATELY}

Appendix Table 8. Regression results using HBD accuracy with negative social judgments as the criterion.

\begin{tabular}{|c|c|c|c|c|c|}
\hline Predictor & $b$ & $\begin{array}{c}b \\
95 \% \mathrm{CI} \\
{[\mathrm{LL}, \mathrm{UL}]}\end{array}$ & $s r^{2}$ & Fit & Difference \\
\hline (Intercept) & $1.81 * *$ & {$[1.60,2.02]$} & & & \\
\hline HBD Accuracy & -0.52 & {$[-2.26,1.22]$} & .00 & & \\
\hline \multirow[t]{2}{*}{ SNS Reactivity } & 0.01 & {$[-0.00,0.03]$} & .01 & & \\
\hline & & & & $\begin{array}{l}R^{2}=.016 \\
95 \% \mathrm{CI}[.00, .07]\end{array}$ & \\
\hline (Intercept) & $1.81 * *$ & {$[1.60,2.02]$} & & & \\
\hline HBD Accuracy & -0.34 & {$[-2.09,1.42]$} & .00 & & \\
\hline SNS Reactivity & 0.01 & {$[-0.01,0.03]$} & .01 & & \\
\hline \multirow[t]{2}{*}{$\begin{array}{l}\text { HBD Accuracy x } \\
\text { SNS Reactivity }\end{array}$} & -0.11 & {$[-0.29,0.07]$} & .01 & & \\
\hline & & & & $\begin{array}{l}R^{2}=.026 \\
95 \% \text { CI[.00,.08] }\end{array}$ & $\begin{array}{l}\Delta R^{2}=.010 \\
95 \% \mathrm{CI}[-.02, .04]\end{array}$ \\
\hline (Intercept) & $1.98 * *$ & {$[1.70,2.25]$} & & & \\
\hline HBD Accuracy & -0.31 & {$[-2.11,1.50]$} & .00 & & \\
\hline SNS Reactivity & 0.01 & {$[-0.01,0.03]$} & .01 & & \\
\hline Age & -0.02 & {$[-0.18,0.15]$} & .00 & & \\
\hline Self-Reported Sex & -0.41 & {$[-0.85,0.02]$} & .02 & & \\
\hline BMI & -0.04 & {$[-0.11,0.03]$} & .01 & & \\
\hline \multirow[t]{2}{*}{$\begin{array}{l}\text { HBD Accuracy x } \\
\text { SNS Reactivity }\end{array}$} & -0.09 & {$[-0.27,0.09]$} & .01 & & \\
\hline & & & & $\begin{array}{l}R^{2}=.058 \\
95 \% \mathrm{CI}[.00, .11]\end{array}$ & $\begin{array}{l}\Delta R^{2}=.033 \\
95 \% \mathrm{CI}[-.02, .09]\end{array}$ \\
\hline
\end{tabular}

Note. Higher criterion values indicate more negative interviewer ratings. All continuous predictors are mean-centered. A significant $b$-weight indicates the beta-weight and semi-partial correlation are also significant. $b$ represents unstandardized regression weights. $s r^{2}$ serves as an effect size estimate and represents the semi-partial correlation squared. $L L$ and $U L$ indicate the lower and upper limits of a confidence interval, respectively. * Indicates $p<.05$. ** indicates $p<.01$. 
Appendix Table 9. Regression results using HBD accuracy with positive social judgments as the criterion.

\begin{tabular}{|c|c|c|c|c|c|}
\hline Predictor & $b$ & $\begin{array}{c}b \\
95 \% \mathrm{CI} \\
{[\mathbf{L L}, \mathrm{UL}]}\end{array}$ & $s r^{2}$ & Fit & Difference \\
\hline (Intercept) & $3.21 * *$ & {$[2.98,3.44]$} & & & \\
\hline HBD Accuracy & -0.88 & {$[-2.79,1.04]$} & .01 & & \\
\hline \multirow[t]{3}{*}{ SNS Reactivity } & -0.00 & {$[-0.02,0.02]$} & .00 & & \\
\hline & & & & $R^{2}=.006$ & \\
\hline & & & & $95 \%$ CI[.00,.04] & \\
\hline (Intercept) & $3.19 * *$ & {$[2.96,3.42]$} & & & \\
\hline HBD Accuracy & -1.35 & {$[-3.25,0.54]$} & .01 & & \\
\hline SNS Reactivity & 0.00 & {$[-0.02,0.02]$} & .00 & & \\
\hline \multirow{2}{*}{$\begin{array}{l}\text { HBD Accuracy x } \\
\text { SNS Reactivity }\end{array}$} & $0.29 * *$ & {$[0.10,0.48]$} & .05 & & \\
\hline & & & & $\begin{array}{l}R^{2}=.059 * \\
95 \% \text { CI[.00,.13] }\end{array}$ & $\begin{array}{l}\Delta R^{2}=.052 * * \\
95 \% \mathrm{CI}[-.01, .12]\end{array}$ \\
\hline (Intercept) & $3.24 * *$ & {$[2.94,3.54]$} & & & \\
\hline HBD Accuracy & -1.10 & {$[-3.06,0.86]$} & .01 & & \\
\hline SNS Reactivity & 0.00 & {$[-0.02,0.02]$} & .00 & & \\
\hline Age & -0.11 & {$[-0.29,0.07]$} & .01 & & \\
\hline Self-Reported Sex & -0.11 & {$[-0.59,0.37]$} & .00 & & \\
\hline BMI & 0.04 & {$[-0.04,0.11]$} & .00 & & \\
\hline \multirow[t]{2}{*}{$\begin{array}{l}\text { HBD Accuracy x } \\
\text { SNS Reactivity }\end{array}$} & $0.28 * *$ & {$[0.09,0.48]$} & .05 & & \\
\hline & & & & $\begin{array}{l}R^{2}=.073 \\
95 \% \mathrm{CI}[.00, .13]\end{array}$ & $\begin{array}{l}\Delta R^{2}=.014 \\
95 \% \mathrm{CI}[-.02, .05]\end{array}$ \\
\hline
\end{tabular}

Note. Higher criterion values indicate more positive interviewer ratings. All continuous predictors are mean-centered. A significant $b$-weight indicates the beta-weight and semi-partial correlation are also significant. $b$ represents unstandardized regression weights. $s r^{2}$ serves as an effect size estimate and represents the semi-partial correlation squared. $L L$ and $U L$ indicate the lower and upper limits of a confidence interval, respectively. ${ }^{*}$ Indicates $p<.05$. ** indicates $p<.01$. 
Appendix Table 10. Regression results using HBD accuracy with negative situation judgments as the criterion.

\begin{tabular}{|c|c|c|c|c|c|}
\hline Predictor & $b$ & $\begin{array}{c}b \\
95 \% \mathrm{CI} \\
{[\mathrm{LL}, \mathrm{UL}]}\end{array}$ & $s r^{2}$ & Fit & Difference \\
\hline (Intercept) & $3.60 * *$ & {$[3.44,3.76]$} & & & \\
\hline HBD Accuracy & -1.10 & {$[-2.42,0.22]$} & .02 & & \\
\hline \multirow[t]{3}{*}{ SNS Reactivity } & 0.01 & {$[-0.01,0.02]$} & .01 & & \\
\hline & & & & $R^{2}=.022$ & \\
\hline & & & & $95 \%$ CI[.00,.08] & \\
\hline (Intercept) & $3.60 * *$ & {$[3.44,3.76]$} & & & \\
\hline HBD Accuracy & -1.15 & {$[-2.49,0.19]$} & .02 & & \\
\hline SNS Reactivity & 0.01 & {$[-0.01,0.02]$} & .01 & & \\
\hline \multirow{2}{*}{$\begin{array}{l}\text { HBD Accuracy } x \\
\text { SNS Reactivity }\end{array}$} & 003 & {$\left[\begin{array}{lllll}-0 & 11 & 0 & 17\end{array}\right]$} & 00 & & \\
\hline & & & & $\begin{array}{l}R^{2}=.023 \\
95 \% \text { CI[.00,.07] }\end{array}$ & $\begin{array}{l}\Delta R^{2}=.001 \\
95 \% \mathrm{CI}[-.01, .01]\end{array}$ \\
\hline (Intercept) & $3.83 * *$ & {$[3.63,4.04]$} & & & \\
\hline HBD Accuracy & -0.92 & {$[-2.25,0.42]$} & .01 & & \\
\hline SNS Reactivity & 0.01 & {$[-0.00,0.02]$} & .01 & & \\
\hline Age & -0.04 & {$[-0.16,0.08]$} & .00 & & \\
\hline Self-Reported Sex & $-0.58 * *$ & {$[-0.90,-0.25]$} & .07 & & \\
\hline BMI & -0.02 & {$[-0.07,0.04]$} & .00 & & \\
\hline \multirow{2}{*}{$\begin{array}{l}\text { HBD Accuracy x } \\
\text { SNS Reactivity }\end{array}$} & 0.05 & {$[-0.08,0.18]$} & .00 & & \\
\hline & & & & $\begin{array}{l}R^{2}=.109 * * \\
95 \% \text { CI }[.01, .18]\end{array}$ & $\begin{array}{l}\Delta R^{2}=.086 * * \\
95 \% \text { CI }[.00, .17]\end{array}$ \\
\hline
\end{tabular}

Note. Higher criterion values indicate more negative situation ratings. All continuous predictors are meancentered. A significant $b$-weight indicates the beta-weight and semi-partial correlation are also significant. $b$ represents unstandardized regression weights. $s r^{2}$ serves as an effect size estimate and represents the semi-partial correlation squared. $L L$ and $U L$ indicate the lower and upper limits of a confidence interval, respectively. $*$ Indicates $p<.05 . * *$ indicates $p<.01$. 
Appendix Table 11. Regression results using HBD accuracy with positive situation judgments as the criterion.

\begin{tabular}{|c|c|c|c|c|c|}
\hline Predictor & $b$ & $\begin{array}{c}b \\
95 \% \mathrm{CI} \\
{[\mathrm{LL}, \mathrm{UL}]}\end{array}$ & $s r^{2}$ & Fit & Difference \\
\hline (Intercept) & $2.20 * *$ & {$[2.04,2.36]$} & & & \\
\hline HBD Accuracy & 0.21 & {$[-1.11,1.53]$} & .00 & & \\
\hline \multirow[t]{3}{*}{ SNS Reactivity } & -0.00 & {$[-0.02,0.01]$} & .00 & & \\
\hline & & & & $R^{2}=.002$ & \\
\hline & & & & $95 \%$ CI[.00,.02] & \\
\hline (Intercept) & $2.20 * *$ & {$[2.04,2.35]$} & & & \\
\hline HBD Accuracy & 0.06 & {$[-1.27,1.39]$} & .00 & & \\
\hline SNS Reactivity & -0.00 & {$[-0.02,0.01]$} & .00 & & \\
\hline \multirow{2}{*}{$\begin{array}{l}\text { HBD Accuracy x } \\
\text { SNS Reactivity }\end{array}$} & 0.09 & {$[-0.05,0.23]$} & .01 & & \\
\hline & & & & $\begin{array}{l}R^{2}=.012 \\
95 \% \mathrm{CI}[.00, .05]\end{array}$ & $\begin{array}{l}\Delta R^{2}=.011 \\
95 \% \mathrm{CI}[-.02, .04]\end{array}$ \\
\hline (Intercept) & $2.00 * *$ & {$[1.79,2.20]$} & & & \\
\hline HBD Accuracy & -0.08 & {$[-1.43,1.26]$} & .00 & & \\
\hline SNS Reactivity & -0.00 & {$[-0.02,0.01]$} & .00 & & \\
\hline Age & -0.01 & {$[-0.13,0.12]$} & .00 & & \\
\hline Self-Reported Sex & $0.50 * *$ & {$[0.17,0.82]$} & .05 & & \\
\hline BMI & 0.03 & {$[-0.03,0.08]$} & .01 & & \\
\hline \multirow[t]{3}{*}{$\begin{array}{l}\text { HBD Accuracy x } \\
\text { SNS Reactivity }\end{array}$} & 0.07 & {$[-0.06,0.20]$} & .01 & & \\
\hline & & & & $R^{2}=.076$ & $\Delta R^{2}=.063^{*}$ \\
\hline & & & & $95 \%$ CI[.00,.13] & $95 \% \mathrm{CI}[-.01, .14]$ \\
\hline
\end{tabular}

Note. Higher criterion values indicate more positive situation ratings. All continuous predictors are meancentered. A significant $b$-weight indicates the beta-weight and semi-partial correlation are also significant. $b$ represents unstandardized regression weights. $s r^{2}$ serves as an effect size estimate and represents the semi-partial correlation squared. $L L$ and $U L$ indicate the lower and upper limits of a confidence interval, respectively. ${ }^{*}$ Indicates $p<.05 . * *$ indicates $p<.01$. 


\section{APPENDIX 6: RESULTS REMOVING OUTLIERS}

Appendix Table 12. Regression results using HBD accuracy with total social judgments as the criterion and removing points with high leverage $(n=157)$.

\begin{tabular}{|c|c|c|c|c|c|}
\hline Predictor & $b$ & $\begin{array}{c}b \\
95 \% \text { CI } \\
{[L L, U L]}\end{array}$ & $s r^{2}$ & Fit & Difference \\
\hline (Intercept) & $3.71 * *$ & {$[3.51,3.90]$} & & & \\
\hline HBD Accuracy & -0.33 & {$[-2.00,1.35]$} & .00 & & \\
\hline \multirow[t]{2}{*}{ SNS Reactivity } & -0.01 & {$[-0.03,0.01]$} & .00 & & \\
\hline & & & & $\begin{array}{l}R^{2}=.006 \\
95 \% \mathrm{CI}[.00, .04]\end{array}$ & \\
\hline (Intercept) & $3.69 * *$ & {$[3.49,3.88]$} & & & \\
\hline HBD Accuracy & -0.36 & {$[-2.01,1.29]$} & .00 & & \\
\hline SNS Reactivity & -0.01 & {$[-0.02,0.01]$} & .00 & & \\
\hline \multirow[t]{2}{*}{$\begin{array}{l}\text { HBD Accuracy x } \\
\text { SNS Reactivity }\end{array}$} & $0.25 *$ & {$[0.05,0.44]$} & .04 & & \\
\hline & & & & $\begin{array}{l}R^{2}=.044 \\
95 \% \mathrm{CI}[.00, .11]\end{array}$ & $\begin{array}{l}\Delta R^{2}=.037 * \\
95 \% \mathrm{CI}[-.02, .10]\end{array}$ \\
\hline (Intercept) & $3.62 * *$ & {$[3.36,3.89]$} & & & \\
\hline HBD Accuracy & -0.26 & {$[-1.98,1.46]$} & .00 & & \\
\hline SNS Reactivity & -0.00 & {$[-0.02,0.01]$} & .00 & & \\
\hline Age & -0.08 & {$[-0.27,0.12]$} & .00 & & \\
\hline $\begin{array}{r}\text { Self-Reported } \\
\text { Sex }\end{array}$ & 0.16 & {$[-0.26,0.57]$} & .00 & & \\
\hline $\mathrm{BMI}$ & 0.04 & {$[-0.03,0.10]$} & .01 & & \\
\hline \multirow[t]{2}{*}{$\begin{array}{l}\text { HBD Accuracy x } \\
\text { SNS Reactivity }\end{array}$} & $0.23 *$ & {$[0.03,0.43]$} & .03 & & \\
\hline & & & & $\begin{array}{l}R^{2}=.057 \\
95 \% \mathrm{CI}[.00, .11]\end{array}$ & $\begin{array}{l}\Delta R^{2}=.013 \\
95 \% \mathrm{CI}[-.02, .05]\end{array}$ \\
\hline
\end{tabular}

Note. Higher criterion values indicate more positive interviewer ratings. All continuous predictors are mean-centered. A significant $b$-weight indicates the beta-weight and semi-partial correlation are also significant. $b$ represents unstandardized regression weights. $s r^{2}$ serves as an effect size estimate and represents the semi-partial correlation squared. $L L$ and $U L$ indicate the lower and upper limits of a confidence interval, respectively. * Indicates $p<.05$. ** indicates $p<.01$. 
Appendix Table 13. Regression results using HBD accuracy with total situation judgments as the criterion and removing points with high leverage $(n=157)$.

\begin{tabular}{|c|c|c|c|c|c|}
\hline Predictor & $b$ & $\begin{array}{c}b \\
95 \% \mathrm{CI} \\
{[\mathrm{LL}, \mathrm{UL}]}\end{array}$ & $s r^{2}$ & Fit & Difference \\
\hline (Intercept) & $2.31 * *$ & {$[2.17,2.45]$} & & & \\
\hline HBD Accuracy & 0.79 & {$[-0.40,1.97]$} & .01 & & \\
\hline \multirow[t]{2}{*}{ SNS Reactivity } & -0.01 & {$[-0.02,0.01]$} & .01 & & \\
\hline & & & & $\begin{array}{l}R^{2}=.017 \\
95 \% \mathrm{CI}[.00, .07]\end{array}$ & \\
\hline (Intercept) & $2.31 * *$ & {$[2.17,2.45]$} & & & \\
\hline HBD Accuracy & 0.78 & {$[-0.40,1.97]$} & .01 & & \\
\hline SNS Reactivity & -0.01 & {$[-0.02,0.01]$} & .01 & & \\
\hline \multirow[t]{2}{*}{$\begin{array}{l}\text { HBD Accuracy x } \\
\text { SNS Reactivity }\end{array}$} & 0.01 & {$[-0.13,0.16]$} & .00 & & \\
\hline & & & & $\begin{array}{l}R^{2}=.017 \\
95 \% \mathrm{CI}[.00, .06]\end{array}$ & $\begin{array}{l}\Delta R^{2}=.000 \\
95 \% \mathrm{CI}[-.00, .00]\end{array}$ \\
\hline (Intercept) & $2.06^{* *}$ & {$[1.88,2.24]$} & & & \\
\hline HBD Accuracy & 0.50 & {$[-0.67,1.67]$} & .00 & & \\
\hline SNS Reactivity & -0.01 & {$[-0.02,0.00]$} & .01 & & \\
\hline Age & 0.02 & {$[-0.11,0.15]$} & .00 & & \\
\hline Self-Reported Sex & $0.61 * *$ & {$[0.32,0.89]$} & .10 & & \\
\hline BMI & 0.02 & {$[-0.03,0.07]$} & .00 & & \\
\hline \multirow[t]{2}{*}{$\begin{array}{l}\text { HBD Accuracy x } \\
\text { SNS Reactivity }\end{array}$} & -0.02 & {$[-0.16,0.12]$} & .00 & & \\
\hline & & & & $\begin{array}{l}R^{2}=.139 * * \\
95 \% \mathrm{CI}[.03, .21]\end{array}$ & $\begin{array}{l}\Delta R^{2}=.122^{* *} \\
95 \% \mathrm{CI}[.03, .22]\end{array}$ \\
\hline
\end{tabular}

Note. Higher criterion values indicate more positive situation ratings All continuous predictors are meancentered. A significant $b$-weight indicates the beta-weight and semi-partial correlation are also significant. $b$ represents unstandardized regression weights. $s r^{2}$ serves as an effect size estimate and represents the semi-partial correlation squared. $L L$ and $U L$ indicate the lower and upper limits of a confidence interval, respectively.* indicates $p<.05$. ** indicates $p<.01$. 


\section{REFERENCES}

Abele, A. E., Ellemers, N., Fiske, S. T., Koch, A., \& Yzerbyt, V. (2021). Navigating the social world: Toward an integrated framework for evaluating self, individuals, and groups. Psychological Review, 128(2), 290-314. https://doi.org/10.1037/rev0000262

Allen, M., \& Tsakiris, M. (2018). The body as first prior: Interoceptive predictive processing and the primacy of self-models. In M. Tsakiris \& H. D. Preester (Eds.), The Interoceptive Mind: From Homeostasis to Awareness. Oxford University Press.

Andersen, J. P., Di Nota, P. M., Beston, B., Boychuk, E. C., Gustafsberg, H., Poplawski, S., \& Arpaia, J. (2018). Reducing lethal force errors by modulating police physiology. Journal of Occupational and Environmental Medicine, 60(10), 867-874. https://doi.org/10.1097/JOM.0000000000001401

Anderson, E., Siegel, E., White, D., \& Barrett, L. F. (2012). Out of sight but not out of mind: Unseen affective faces influence evaluations and social impressions. Emotion, 12(6), 1210-1221. https://doi.org/10.1037/a0027514

Atzil, S., Gao, W., Fradkin, I., \& Barrett, L. F. (2018). Growing a social brain. Nature Human Behaviour, 2(9), 624-636. https://doi.org/10.1038/s41562-018-0384-6

Aviezer, H., Trope, Y., \& Todorov, A. (2012). Body cues, not facial expressions, discriminate between intense positive and negative emotions. Science, 338(6111), 1225-1229. https://doi.org/10.1126/science. 1224313

Babo-Rebelo, M., \& Tallon-Baudry, C. (2018). Interoceptive signals, brain dynamics, and subjectivity. In M. Tsakiris \& H. D. De Preester (Eds.), The Interoceptive Mind: From Homeostasis to Awareness. Oxford University Press.

Babo-Rebelo, M., Buot, A., \& Tallon-Baudry, C. (2019). Neural responses to heartbeats distinguish self from other during imagination. NeuroImage, 191, 10-20. https://doi.org/10.1016/j.neuroimage.2019.02.012

Balcetis, E., \& Dunning, D. (2006). See what you want to see: Motivational influences on visual perception. Journal of Personality and Social Psychology, 91(4), 612-625. https://doi.org/10.1037/0022-3514.91.4.612

Barrett, L. F. (2017). The theory of constructed emotion: An active inference account of interoception and categorization. Social Cognitive and Affective Neuroscience, 12(11), 1833. https://doi.org/10.1093/scan/nsx060

Barrett, L. F., \& Bar, M. (2009). See it with feeling: Affective predictions during object perception. Philosophical Transactions of the Royal Society B: Biological Sciences, 364(1521), 1325-1334. https://doi.org/10.1098/rstb.2008.0312

Barrett, L. F., \& Bliss-Moreau, E. (2009). Affect as a psychological primitive. Advances in Experimental Social Psychology, 41, 167-218. https://doi.org/10.1016/S0065-2601(08)00404-8 
Berntson, G. G., Quigley, K. S., Norman, G. J., \& Lozano, D. L. (2017). Cardiovascular psychophysiology. In Handbook of psychophysiology, 4th ed (pp. 183-216). Cambridge University Press.

Bouffard, J. A., \& Miller, H. A. (2014). The role of sexual arousal and overperception of sexual intent within the decision to engage in sexual coercion. Journal of Interpersonal Violence, 29(11), 1967-1986. https://doi.org/10.1177/0886260513515950

Brooks, J. A., Chikazoe, J., Sadato, N., \& Freeman, J. B. (2019). The neural representation of facialemotion categories reflects conceptual structure. Proceedings of the National Academy of Sciences of the United States of America, 116(32), 15861-15870. https://doi.org/10.1073/pnas.1816408116

Cacioppo, J. T., Louis, T. G., \& Berntson, G. G. (Eds.). (2017). Handbook of Psychophysiology (4th ed.). Cambridge University Press.

Cantor, J. R., Zillmann, D., \& Bryant, J. (1975). Enhancement of experienced sexual arousal in response to erotic stimuli through misattribution of unrelated residual excitation. Journal of Personality and Social Psychology, 32(1), 69-75. https://doi.org/10.1037/h0076784

Clore, G. L., \& Huntsinger, J. R. (2007). How emotions inform judgment and regulate thought. Trends in Cognitive Sciences, 11(9), 393-399. https://doi.org/10.1016/j.tics.2007.08.005

Dickerson, S. S., \& Kemeny, M. E. (2004). Acute stressors and cortisol responses: A theoretical integration and synthesis of laboratory research. Psychological Bulletin, 130(3), 355-391. https://doi.org/10.1037/0033-2909.130.3.355

Dutton, D. G., \& Aron, A. P. (1974). Some evidence for heightened sexual attraction under conditions of high anxiety. Journal of Personality and Social Psychology, 30(4), 510-517. https://doi.org/10.1037/h0037031

Eisenberger, N. I., Moieni, M., Inagaki, T. K., Muscatell, K. A., \& Irwin, M. R. (2017). In sickness and in health: The co-regulation of inflammation and social behavior. Neuropsychopharmacology, 42(1), 242-253. https://doi.org/10.1038/npp.2016.141

Erdfelder, E., Faul, F., \& Buchner, A. (1996). GPOWER: A general power analysis program. Behavior Research Methods, Instruments \& Computers, 28(1), 1-11. https://doi.org/10.3758/BF03203630

Feldman, M., Siegel, E., Feldman Barrett, L., Quigley, K., \& Wormwood, J. (under review). Affect and social judgment: The roles of physiological reactivity and interoceptive sensitivity.

Feldman-Hall, O., \& Shenhav, A. (2019). Resolving uncertainty in a social world. Nature Human Behaviour, 3(5), 426-435. https://doi.org/10.1038/s41562-019-0590-X

Fiske, S. T. (1998). Stereotyping, prejudice, and discrimination. In The handbook of social psychology, Vols. 1-2, 4th ed (pp. 357-411). McGraw-Hill.

Grabauskaitè, A., Baranauskas, M., \& Griškova-Bulanova, I. (2017). Interoception and gender: What aspects should we pay attention to? Consciousness and Cognition, 48, 129-137. https://doi.org/10.1016/j.concog.2016.11.002 
Haller, J., Raczkevy-Deak, G., Gyimesine, K. P., Szakmary, A., Farkas, I., \& Vegh, J. (2014). Cardiac autonomic functions and the emergence of violence in a highly realistic model of social conflict in humans. Frontiers in Behavioral Neuroscience, 8, 364. https://doi.org/10.3389/fnbeh.2014.00364

Hehman, E., Stolier, R. M., Freeman, J. B., Flake, J. K., \& Xie, S. Y. (2019). Toward a comprehensive model of face impressions: What we know, what we do not, and paths forward. Social and Personality Psychology Compass, 13(2), e12431. https://doi.org/10.1111/spc3.12431

Hinton, P. (2017). Implicit stereotypes and the predictive brain: Cognition and culture in "biased" person perception. Palgrave Communications, 3(1), 1-9. https://doi.org/10.1057/palcomms.2017.86

Khalsa, S., Rudrauf, D., \& Tranel, D. (2009). Interoceptive awareness declines with age. Psychophysiology, 46(6), 1130-1136. https://doi.org/10.1111/j.1469-8986.2009.00859.x

Khalsa, S. S., Adolphs, R., Cameron, O. G., Critchley, H. D., Davenport, P. W., Feinstein, J. S., Feusner, J. D., Garfinkel, S. N., Lane, R. D., Mehling, W. E., Meuret, A. E., Nemeroff, C. B., Oppenheimer, S., Petzschner, F. H., Pollatos, O., Rhudy, J. L., Schramm, L. P., Simmons, W. K., Stein, M. B., ... Paulus, M. P. (2018). Interoception and mental health: A roadmap. Biological Psychiatry. Cognitive Neuroscience and Neuroimaging, 3(6), 501-513. https://doi.org/10.1016/j.bpsc.2017.12.004

Khalsa, S. S., Rudrauf, D., Hassanpour, M. S., Davidson, R. J., \& Tranel, D. (2020). The practice of meditation is not associated with improved interoceptive awareness of the heartbeat. Psychophysiology, 57(2), e13479. https://doi.org/10.1111/psyp.13479

Kleckner, I. R., Wormwood, J. B., Simmons, W. K., Barrett, L. F., \& Quigley, K. S. (2015). Methodological recommendations for a heartbeat detection-based measure of interoceptive sensitivity. Psychophysiology, 52(11), 1432-1440. https://doi.org/10.1111/psyp.12503

Kudielka, B. M., Hellhammer, D. H., \& Kirschbaum, C. (2007). Ten years of research with the Trier Social Stress Test—revisited. In Social neuroscience: Integrating biological and psychological explanations of social behavior (pp. 56-83). The Guilford Press.

Leyva, P., \& Hill, S. E. (2018). Unpredictability, body awareness, and eating in the absence of hunger: A cognitive schemas approach. Health Psychology: Official Journal of the Division of Health Psychology, American Psychological Association, 37(7), 691-699. https://doi.org/10.1037/hea0000634

Long, J. (2019). Interactions: Comprehensive, user-friendly toolkit for probing interactions (R package version 1.1.0) [Computer software]. https://cran.r-project.org/package=interactions

MacCormack, J. K., \& Lindquist, K. A. (2019). Feeling hangry? When hunger is conceptualized as emotion. Emotion, 19(2), 301-319. https://doi.org/10.1037/emo0000422

MacCormack, J. K., Castro, V. L., Halberstadt, A. G., \& Rogers, M. L. (2020). Mothers' interoceptive knowledge predicts children's emotion regulation and social skills in middle childhood. Social Development, 29(2), 578-599. https://doi.org/10.1111/sode.12418 
Moeini-Jazani, M., Knoeferle, K., de Molière, L., Gatti, E., \& Warlop, L. (2017). Social power increases interoceptive accuracy. Frontiers in Psychology, 8. https://doi.org/10.3389/fpsyg.2017.01322

Mohammad, S. (2018). Obtaining reliable human ratings of valence, arousal, and dominance for 20,000 English words. Proceedings of the 56th Annual Meeting of the Association for Computational Linguistics (Volume 1: Long Papers), 174-184. https://doi.org/10.18653/v1/P18-1017

Murphy, J., Viding, E., \& Bird, G. (2019). Does atypical interoception following physical change contribute to sex differences in mental illness? Psychological Review, 126(5), 787-789. https://doi.org/10.1037/rev0000158

Paulus, M. P., Feinstein, J. S., \& Khalsa, S. S. (2019). An active inference approach to interoceptive psychopathology. Annual Review of Clinical Psychology, 15(1), 97-122. https://doi.org/10.1146/annurev-clinpsy-050718-095617

Posner, J., Russell, J. A., \& Peterson, B. S. (2005). The circumplex model of affect: An integrative approach to affective neuroscience, cognitive development, and psychopathology. Development and Psychopathology, 17(3), 715-734. https://doi.org/10.1017/S0954579405050340

Proffitt, D. R., Stefanucci, J., Banton, T., \& Epstein, W. (2003). The role of effort in perceiving distance. Psychological Science, 14(2), 106-112. https://doi.org/10.1111/1467-9280.t01-1-01427

Proffitt Leyva, R. P., \& Hill, S. E. (2018). Unpredictability, body awareness, and eating in the absence of hunger: A cognitive schemas approach. Health Psychology: Official Journal of the Division of Health Psychology, American Psychological Association, 37(7), 691-699. https://doi.org/10.1037/hea0000634

Provenzano, J., Verduyn, P., Daniels, N., Fossati, P., \& Kuppens, P. (2019). Mood congruency effects are mediated by shifts in salience and central executive network efficiency. Social Cognitive and Affective Neuroscience, 14(9), 987-995. https://doi.org/10.1093/scan/nsz065

Qu, M., Zhang, Y., Webster, J. G., \& Tompkins, W. J. (1986). Motion artifact from spot and band electrodes during impedance cardiography. IEEE Transactions on Biomedical Engineering, BME-33(11), 1029-1036. https://doi.org/10.1109/TBME.1986.325869

Quadt, L., Garfinkel, S. N., Mulcahy, J. S., Larsson, D. E., Silva, M., Jones, A.-M., Strauss, C., \& Critchley, H. D. (2021). Interoceptive training to target anxiety in autistic adults (ADIE): A single-center, superiority randomized controlled trial. EClinicalMedicine, 39, 101042. https://doi.org/10.1016/j.eclinm.2021.101042

R Core Team. (2019). R: A language and environment for statistical computing. [R Foundation for Statistical Computing]. https://www.R-project.org/

Reents, J., Seidel, A.-K., Wiesner, C. D., \& Pedersen, A. (2020). The effect of hunger and satiety on mood-related food craving. Frontiers in Psychology, 11, 2834. https://doi.org/10.3389/fpsyg.2020.568908

Rominger, C., Graßmann, T. M., Weber, B., \& Schwerdtfeger, A. R. (2021). Does contingent biofeedback improve cardiac interoception? A preregistered replication of Meyerholz, Irzinger, Withöft, 
Gerlach, and Pohl (2019) using the heartbeat discrimination task in a randomised control trial. PLOS ONE, 16(3), e0248246. https://doi.org/10.1371/journal.pone.0248246

Satpute, A. B., Kragel, P. A., Barrett, L. F., Wager, T. D., \& Bianciardi, M. (2019). Deconstructing arousal into wakeful, autonomic and affective varieties. Neuroscience Letters, 693, 19-28. https://doi.org/10.1016/j.neulet.2018.01.042

Schwarz, N., \& Clore, G. L. (1983). Mood, misattribution, and judgments of well-being: Informative and directive functions of affective states. Journal of Personality and Social Psychology, 45(3), 513523. https://doi.org/10.1037/0022-3514.45.3.513

Siegel, E. H., \& Stefanucci, J. K. (2011). A little bit louder now: Negative affect increases perceived loudness. Emotion, 11(4), 1006-1011. https://doi.org/10.1037/a0024590

Silge, J., \& Robinson, D. (2016). tidytext: Text Mining and Analysis Using Tidy Data Principles in R. The Journal of Open Source Software, 1(3), 37. https://doi.org/10.21105/joss.00037

Sterling, P. (2004). Principles of allostasis: Optimal design, predictive regulation, pathophysiology, and rational therapeutics. In J. Schulkin (Ed.), Allostasis, Homeostasis, and the Costs of Physiological Adaptation (1st ed., pp. 17-64). Cambridge University Press. https://doi.org/10.1017/CBO9781316257081.004

Sterling, P. (2012). Allostasis: A model of predictive regulation. Physiology \& Behavior, 106(1), 5-15. https://doi.org/10.1016/j.physbeh.2011.06.004

Sterling, P., \& Laughlin, S. (2015). Principles of Neural Design. MIT Press.

Tajadura-Jiménez, A., \& Tsakiris, M. (2014). Balancing the "inner" and the "outer" self: Interoceptive sensitivity modulates self-other boundaries. Journal of Experimental Psychology. General, 143(2), 736-744. https://doi.org/10.1037/a0033171

Thornton, M. A., \& Tamir, D. I. (2020). People represent mental states in terms of rationality, social impact, and valence: Validating the 3d Mind Model. Cortex; a Journal Devoted to the Study of the Nervous System and Behavior, 125, 44-59. https://doi.org/10.1016/j.cortex.2019.12.012

Todorov, A., Olivola, C. Y., Dotsch, R., \& Mende-Siedlecki, P. (2015). Social attributions from faces: Determinants, consequences, accuracy, and functional significance. Annual Review of Psychology, 66(1), 519-545. https://doi.org/10.1146/annurev-psych-113011-143831

Tsakiris, M., Tajadura-Jiménez, A., \& Costantini, M. (2011). Just a heartbeat away from one's body: Interoceptive sensitivity predicts malleability of body-representations. Proceedings. Biological Sciences, 278(1717), 2470-2476. https://doi.org/10.1098/rspb.2010.2547

Uleman, J. S., Adil Saribay, S., \& Gonzalez, C. M. (2008). Spontaneous inferences, implicit impressions, and implicit theories. Annual Review of Psychology, 59(1), 329-360. https://doi.org/10.1146/annurev.psych.59.103006.093707

Waytz, A., Gray, K., Epley, N., \& Wegner, D. M. (2010). Causes and consequences of mind perception. Trends in Cognitive Sciences, 14(8), 383-388. https://doi.org/10.1016/j.tics.2010.05.006 
Whitehead, W. E., Drescher, V. M., Heiman, P., \& Blackwell, B. (1977). Relation of heart rate control to heartbeat perception. Biofeedback and Self-Regulation, 2(4), 317-392.

Wieser, M. J., \& Brosch, T. (2012). Faces in context: A review and systematization of contextual influences on affective face processing. Frontiers in Psychology, 0. https://doi.org/10.3389/fpsyg.2012.00471

Wormwood, J. B., Siegel, E. H., Kopec, J., Quigley, K. S., \& Barrett, L. F. (2018). You are what I feel: A test of the affective realism hypothesis. Emotion, 19(5), 788-798.

https://doi.org/10.1037/emo0000484 